\begin{tabular}{|l|l|l|l|l|l|}
\hline MUNIBE Antropologia-Arkeologia & $n^{\circ} 69$ & $239-256$ & DONOSTIA & 2018 & ISSN 1132-2217 • eISSN 2172-4555 \\
\hline
\end{tabular}

\title{
Evidencias de ocupación antigua en núcleos rurales actualmente habitados: el proyecto arqueológico de Aizarna (Gipuzkoa)
}

\section{Evidence for ancient occupation in currently inhabited rural settlements: the archaeological project of Aizarna (Gipuzkoa)}

PALABRAS CLAVES: Paisaje rural, comunidades vivas, resiliencia, geoarqueología, antracología. GAKO-HITZAK: Landa-paisaia, komunitate biziak, erresilientzia, geoarkeologia, antrakologia. KEY WORDS: Rural landscape, living communities, resilience, geoarchaeology, anthracology.

\section{Josu NARBARTE HERNÁNDEZ(1), Ander RODRÍGUEZ LEJARZA(2) Riccardo SANTERAMO(1), Juan Antonio QUIRÓS CASTILLO(1) y Eneko IRIARTE AVILÉS ${ }^{(3)}$}

\section{RESUMEN}

El estudio arqueológico de las comunidades rurales actualmente habitadas ofrece la posibilidad de abordar una serie de problemas historiográficos hasta ahora poco explorados. Este artículo discute los problemas, los métodos y los resultados que pueden derivarse de la investigación arqueológica de los pueblos actuales y presenta la metodología transdisciplinar que ha sido aplicada en las recientes intervenciones llevadas a cabo en el área de Erretorekoa (Aizarna, Gipuzkoa). Lejos de los marcos interpretativos tradicionales, los resultados obtenidos revelan que una parte del poblamiento rural actual pudo originarse en época antigua, evidenciando la resiliencia del mismo. En este sentido, es necesario desarrollar marcos conceptuales adecuados para el reconocimiento, estudio e interpretación de este tipo de registros, mediante el diseño de metodologías específicas que permitan superar las limitaciones impuestas por la propia continuidad de la ocupación en estos contextos.

\section{LABURPENA}

Landa-komunitate bizien ikerketa arkeologikoak orain arte gutxi landu izan diren zenbait arazo historiografikori heltzeko aukera eskaintzen du. Lan honetan, egungo herrien ikerketari lotutako arazoak, metodoak eta emaitza potentzialak jorratzen dira; eta, testuinguru honetan, berriki Erretorekoa inguruan (Aizarna, Gipuzkoa) gauzatu diren esku-hartzeetan erabili den metodologia transdisziplinarra azaltzen da. Ohiko irizpide teorikoetatik urrun, proiektu honetako emaitzek erakusten dute egungo landa-populamenduaren zati bat behintzat Antzinaroan egituratu ahal izan zela, laborari-gizarte hauen erresilientzia-gaitasuna agerian utziz. Zentzu honetan, beharrezkoa izango da erregistro mota honen ezagutza, ikerketa eta interpretazioa garatzeko oinarri teoriko egokiak sortzea, eta herri hauen okupazio-jarraipenak berak haien ikerketari ezartzen dizkion oztopoak gainditzeko moduko metodologiak garatzea.

\section{ABSTRACT}

Archaeological research on currently inhabited settlements offers the possibility to face a set of historiographic problems, like those linked to the resilience of rural communities, that have not been deeply explored so far. The present paper aims to discuss the problems, methods and results that can be expected from archaeological intervention in living villages, and introduces the transdisciplinary methodology implemented in the research project that is taking place in the village of Aizarna (Gipuzkoa), whose existence is attested since, at least, the Late Middle Ages. The area of interest is the so-called Erretorekoa, close to the parish church, where a combination of high resolution stratigraphy using geoarchaeological methods, anthracology, and archaeological excavation, has allowed to recognise an occupational sequence dating back to the Roman period. Far from the traditional interpretative background, this fact demonstrates that at least one part of the rural settlement could be originated during the Antiquity, thus evidencing a great resilience. In this sense, new conceptual frameworks should be developed in order to adequately recognise, study and interpret such records, by means of specific methodologies that should allow overcoming the limitations imposed by the occupational continuity of these contexts.

\footnotetext{
(1) Universidad del País Vasco / Euskal Herriko Unibertsitatea. Grupo de Investigación en Patrimonio y Paisajes Culturales. Centro de Investigación Micaela Portilla, calle Justo Vélez de Elorriaga 1, 01006 Vitoria-Gasteiz. Email: josu.narbarte@ehu.eus, riccardo.santeramo@outlook.com, quiros. castillo@ehu.eus

(2) Universidad del País Vasco / Euskal Herriko Unibertsitatea. Email: arodriguezlejarza@gmail.com

(3) Universidad de Burgos. Laboratorio de Evolución Humana. Edificio I+D+i, plaza Misael Bañuelos s/n, 09001 Burgos. Email: eiriarte@ubu.es
} 


\section{INTRODUCCIÓN}

En las últimas décadas se ha producido una profunda renovación de los estudios sobre el poblamiento y los paisajes rurales en toda Europa, resultado de la convergencia de varios factores, entre los que destacan la acción positiva de la arqueología preventiva, la revisión de los paradigmas historiográficos dominantes, la construcción de una nueva agenda de investigación o la creación de nuevos proyectos de intervención patrimonial. Las síntesis regionales o nacionales realizadas en numerosos contextos europeos constituyen, sin duda alguna, el mejor reflejo de esta transformación, en la que el medievalismo ha tenido un protagonismo destacado (p. ej. Hamerow 2002; 2012; Faure-Boucharlat 2001; Francovich \& Hodges 2003; Peytremann 2003; Valenti 2004; Gentili \& Lefèvre 2009; Valais 2012). Estos trabajos han puesto de relieve la gran complejidad social que caracteriza el medio rural, recalcando la necesidad de elaborar nuevos marcos conceptuales que permitan reconsiderar y resignificar estos espacios desde una perspectiva diacrónica y holística, superando las clásicas divisiones académicas en el marco de una arqueología de los paisajes (p. ej. Johnson 2006; Kluiving \& Guttmann-Bond 2012).

Estas nuevas narrativas han sido construidas, en prácticamente todos los casos, a partir del análisis de lugares despoblados que han sido indagados a través de distintos tipos de proyectos arqueológicos. Sin embargo, en los últimos años se han producido importantes novedades metodológicas y conceptuales, entre las que destaca una nueva corriente de investigación que ha llamado la atención sobre la oportunidad de analizar los lugares aún habitados. Varios son los motivos que han impulsado esta línea de trabajo. En primer lugar, el giro postprocesual en la Arqueología ha determinado una mayor atención hacia la dimensión social de la práctica arqueológica, lo que se ha traducido en posiciones como la denominada 'arqueología pública' y en la realización de proyectos arqueológicos que buscan la implicación directa de las comunidades locales, no solo como receptoras pasivas de productos académicos, sino también como sujetos activos en los procesos de construcción social del conocimiento (Moshenska 2017). En segundo lugar, la cimentación de un conocimiento denso de los paisajes locales precisa del uso de fuentes, percepciones y formas de interacción que forman parte de la memoria social local, por lo que la intervención en espacios poblados no solamente es útil y conveniente, sino también necesaria. En tercer lugar, se ha comprendido que, si bien el estudio de lugares despoblados favorece la realización de intervenciones arqueológicas a gran escala sin generar tensiones con las comunidades, también es cierto que los resultados que proporciona son en gran medida parciales, puesto que se refieren a localidades que, por distintos motivos, terminaron fracasando. Es cierto que, en ocasiones, la arqueología urbana ha proporcionado registros de gran interés que pueden, en cierto modo, compensar esta parcialidad, pero se lleva a cabo en lugares que tienen un estatuto superior al de pueblos y aldeas, por lo que ofrecen otro punto de vista parcial y de limitada representatividad.

Aunque en un reciente encuentro especializado dedicado a la arqueología de los pueblos aún habitados se pudo observar hasta qué punto esta temática se ha ido desarrollando en los últimos decenios en numerosos países europeos ${ }^{1}$, no cabe duda de que la mayor parte de los trabajos realizados hasta el momento se han Ilevado a cabo en el Reino Unido, contribuyendo notablemente a enriquecer el conocimiento sobre los paisajes rurales (p. ej. Rippon 2008; 2009). Uno de los proyectos más relevantes se ha desarrollado en el este de Inglaterra (CORS Project: Currently Occupied Rural Settlement), donde se han indagado más de 53 comunidades rurales a través de la realización de más de 1.500 pequeños sondeos, que han permitido definir patrones regionales de la conformación y transformación de los asentamientos rurales con una profundidad de análisis similar o superior a la realizada a través de la excavación o la prospección de lugares despoblados (Lewis 2007; 2014; 2017). Otro ejemplo de gran interés es el importante proyecto llevado a cabo en Shapwick (Somerset), que ha permitido indagar 10.000 años de historia de un pueblo y una parroquia inglesa aún habitada. Se trata de un proyecto altamente innovador en términos metodológicos y conceptuales, que ha implicado asimismo a la comunidad local de manera fructífera (Aston \& Gerrard 2013).

En cambio, este tipo de estudios aún son muy escasos en la Península Ibérica. Sin duda destacan por su carácter pionero los trabajos que se están realizando en las aldeas asturianas de Vigaña d'Arcéu (Belmonte de Miranda) y Villanueva (Santo Adriano), que están permitiendo no solo historiar los paisajes y los pueblos actuales desde la prehistoria hasta nuestros días, sino que sobre todo generar prácticas de arqueología comunitaria de gran impacto a escala local (Fernández-Mier et al. 2013; 2014; Fernández-Fernández 2014; Fernández-Mier \& Alonso-González 2016). Además, desde un punto de vista más teórico, estos trabajos invitan a abordar la cuestión de la resiliencia o vulnerabilidad de las comunidades rurales como un factor crítico para la comprensión del medio rural (Curtis 2014).

El objetivo de este trabajo consiste en presentar los resultados preliminares de un nuevo proyecto de investigación arqueológica que se está desarrollando en la vertiente cantábrica del País Vasco (Bizkaia y Gipuzkoa). Se trata de un territorio caracterizado por la práctica ausencia de despoblados, así como por la

\footnotetext{
${ }^{1}$ https://archaeologymedievalvillages.wordpress.com/ [consultado: 11-06-2018]. Las actas del coloquio se encuentran actualmente en prensa.
} 
larga permanencia de distintas formas de articulación de las comunidades rurales, en el marco de un paisaje rural fuertemente resiliente. Así, el punto de partida del proyecto ha sido el de explorar la dimensión diacrónica de los paisajes actualmente en uso, evaluando los factores que pueden permitir interpretar las continuidades, discontinuidades y transformaciones de los paisajes en el marco de la larga duración. Para ello se ha desarrollado un protocolo arqueológico que permite intervenir en espacios vivos construyendo registros arqueológicos de complejidad e intensidad creciente en un marco de fuerte interacción con las comunidades locales. En las líneas que siguen se presentan las metodologías implementadas y los resultados preliminares obtenidos en una primera intervención en la localidad de Aizarna (Gipuzkoa), para proceder a continuación a una interpretación del registro arqueológico y a una discusión de lo que este representa en el contexto comarcal y regional para el periodo considerado. Finalmente, en la conclusión se abordan las aportaciones y límites que se derivan de este tipo de intervenciones, y se propone una serie de vías futuras de actuación e interpretación.

\section{2. ÁREA DE ESTUDIO}

Hasta la fecha, los estudios arqueológicos sobre los espacios rurales del área cantábrica del País Vasco se han articulado a partir del estudio de iglesias, cementerios y elementos materiales heredados de un pasado lejano, que actúan como ventanas temporales a través de las cuales es posible analizar largas secuencias de ocupación (p. ej. García-Camino 2002, Etxezarraga-Ortuondo 2013-2016). En cambio, los trabajos que tienen como fin principal el análisis de los paisajes rurales en su dimensión diacrónica son mucho menos frecuentes. Entre las razones que pueden explicar estas carencias hay que señalar, en primer lugar, la casi total ausencia de lugares despoblados que constituyen, tal y como se ha señalado, el escenario privilegiado para el análisis del poblamiento rural y, en ocasiones, también de porciones de paisajes históricos. En segundo lugar, las prácticas agrarias y ganaderas actuales no facilitan la visibilidad de los restos arqueológicos enterrados, tal y como ha ocurrido en otros espacios peninsulares. Pero, además, la noción misma de 'yacimiento' que se utiliza en instancias tanto administrativas como investigadoras dificulta la posibilidad de conceptualizar en términos arqueológicos un paisaje de aldea, un espacio cultivado, una red de caseríos o un valle actualmente habitado. La escasa visibilidad de elementos arqueológicos 'no convencionales' (terrazas agrarias, espacios de cultivo, manchas forestales, red caminera, etc.) que permitan definir una noción extendida de yacimiento determina, así, que en la práctica solamente los entornos monumentalizados (iglesias, caseríos entendidos como arquitecturas, etc.) estén adecuadamente inventariados y reconocidos como elementos patrimoniales. No obstante, los estudios realizados desde la perspectiva de la arqueología agraria muestran la necesidad de redefinir completamente no solo la noción misma de 'yacimiento', sino en general las formas de conceptualizar los paisajes rurales, las relaciones con las poblaciones locales y, en general, la práctica de la arqueología rural (p. ej. Ruiz del Árbol 2006; Orejas 2006; Kirchner 2010; Fernández-Mier \& Alonso-González 2016).

Teniendo en cuenta estas perspectivas, se ha decidido intervenir en un contexto rural de Gipuzkoa que contase con un cierto volumen de documentación histórica, con una cierta predisposición por parte de las entidades locales y con posibilidades para desarrollar un proyecto de esta naturaleza. Aizarna es una pequeña localidad situada a medio camino entre la costa cantábrica y la sierra de Hernio, una de las principales cadenas montañosas del territorio. Se trata de un entorno rural altamente antropizado, donde las áreas de hábitat y cultivo se concentran en el fondo de una pequeña depresión endorreica de origen kárstico atravesada por una pequeña falla y drenada por varias dolinas alineadas alrededor de la misma (Ugalde 1984) (fig. 1). En 2017 contaba 308 habitantes (EUSTAT, Estadística municipal de habitantes), distribuidos entre un pequeño núcleo agrupado en torno a la iglesia parroquial de Santa María, por un lado, y una serie de caseríos dispersos por toda la cuenca, por otro.

A la luz de las fuentes documentales, puede establecerse que esta disposición espacial se hallaba formada, a grandes rasgos, para la segunda mitad del siglo XIV. En 1383, la comunidad de Aizarna queda englobada en el territorio de la nueva villa de Zestoa ${ }^{2}$, fundada junto al río Urola a unos $3 \mathrm{~km}$ de distancia de Aizarna. A lo largo de los siglos XV y XVI puede rastrearse ya la presencia de la mayoría de casas de vecindad que siguen existiendo en la actualidad ${ }^{3}$. La iglesia parroquial de Santa María, documentada como tal desde al menos el siglo XIV, en su fábrica actual data también del siglo XVI (Dávila 1990-1991). Sin embargo, no existen elementos diagnósticos que permitan establecer si este desarrollo bajomedieval se dio sobre una aldea previa u otro tipo de ocupaciones, ni tampoco las bases económicas sobre las que pudo darse tal desarrollo. Por ello, la realización de intervenciones arqueológicas en el seno del espacio habitado actual se plantea como la vía más adecuada para ampliar y desarrollar el conocimiento de su secuencia ocupacional, proporcionando claves interesantes para la comprensión de las cuestiones planteadas.

\footnotetext{
2 Archivo Municipal de Zestoa, s/f (Ayerbe \& Elorza 2008, doc. 5).

${ }^{3}$ Libro de amojonamiento jurisdiccional (1479/1506), Archivo Municipal de Zestoa, C.I.1.5.4. Expediente sobre el encabezamiento de millares en las casas de la jurisdicción de la villa de Cestona (1542), Archivo Municipal de Zestoa, B.I.1.9.1.
} 


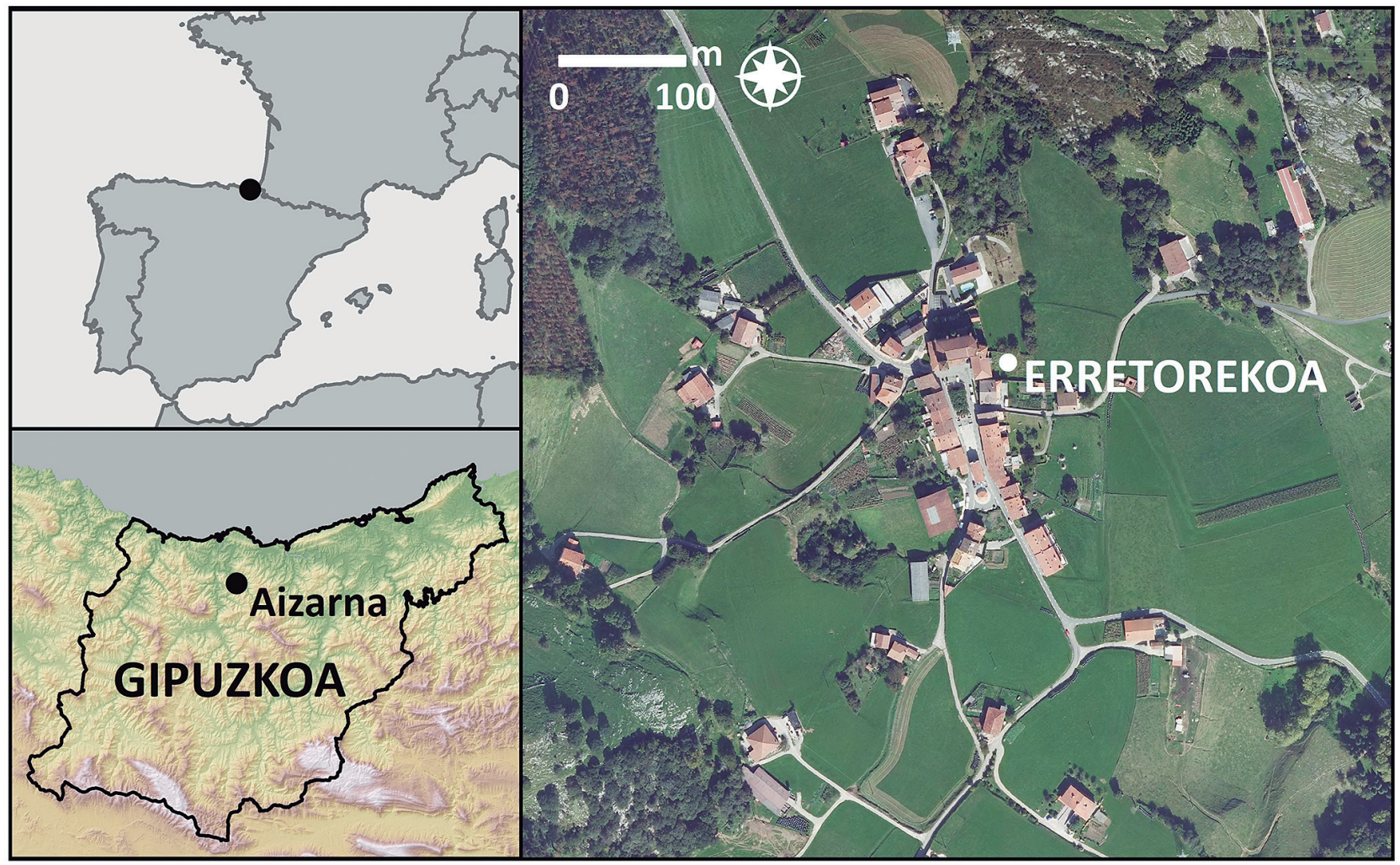

Fig. 1. Localización del área de Erretorekoa en Aizarna. Base cartográfica: Eurostat, PNOA, GeoEuskadi. Elaboración propia. / Location of the area of Erretorekoa within the village of Aizarna. Cartographic basis: PNOA, GeoEuskadi. Authors' elaboration.

Las características del espacio local favorecen dichas intervenciones, ya que toda la cuenca se caracteriza por una intensa modificación topográfica que ha facilitado la formación de registros edáficos de gran potencia, facilitando la preservación de paleosuelos y ocupaciones antiguas. Este es el caso del área de Erretorekoa, situada en una zona central del pueblo, la trasera de la casa rectoral, a escasos metros de la plaza y de la iglesia parroquial. Esta parcela, usada hasta mediados del siglo XX como huerta y campo de cultivo, se eleva más de un metro por encima de los campos vecinos, situados en el borde de la dolina de Zuloeta, uno de los principales sumideros de toda la depresión kárstica circundante

\section{METODOLOGÍA}

Uno de los principales problemas al que se enfrenta la investigación arqueológica en los núcleos rurales habitados es el de identificar una metodología compatible con los usos actuales que permita indagar la potencialidad de los depósitos arqueológicos. Hasta el momento, la mayor parte de los proyectos han apostado por realizar un número más o menos amplio de sondeos arqueológicos de extensión limitada en distintos espacios, con el fin de dirimir aspectos como la existencia o ausencia de evidencias de ocupación en determinados períodos, las transformaciones funcionales de dichos espacios, el impacto de determinados eventos históricos significativos o los procesos de abandono parcial o total de áreas rurales. Así, por ejemplo, en el caso del CORS Project realizado por C. Lewis en el este de Inglaterra, se ha estimado que es preciso realizar al menos 30 pequeños sondeos por localidad. La cuantificación cualitativa de los hallazgos cerámicos, combinados en ocasiones con la realización de análisis de fosfatos, ha permitido analizar con gran detalle la historia de numerosas comunidades (Lewis 2007) y abordar temas como la continuidad entre el período romano y medieval, el proceso de formación de las aldeas en época anglosajona, la nucleación del siglo XII o el impacto de la peste en el siglo XIV (Lewis 2014). También en las aldeas asturianas de Vigaña y Villanueva de Santo Adriano se han realizado numerosos sondeos de distintas dimensiones, tanto en los espacios habitados (huertos, solares abandonados), como en los espacios de cultivo (campos, prados, seles, etc.), lo que ha proporcionado informaciones críticas para comprender las transformaciones de estos espacios (Fernández-Mier et al. 2014).

En Aizarna se ha optado por experimentar una nueva estrategia de intervención, basada en la realización de sondeos geoarqueológicos, por un lado, y de excavaciones de extensión limitada, por otro. Mediante este procedimiento se ha pretendido obtener secuencias extensivas, aunque discontinuas, de los procesos de formación del paisaje rural a escala local, con una alta resolución estratigráfica. A continuación, se explica el procedimiento seguido. 


\subsection{Primera intervención: sondeos geoarqueo- lógicos}

En octubre de 2016 se llevó a cabo una primera intervención de carácter diagnóstico, basada en la realización de varios sondeos geoarqueológicos repartidos por todo el fondo de la cuenca de Aizarna. Para ello se usó una perforadora mecánica portátil Van Walt/Eijkelkamp, que permite la recuperación de testigos, en este caso de $2 \mathrm{~m}$ de profundidad, en maniobras de 1 $\mathrm{m}$. Se trata de un procedimiento en gran medida experimental en este tipo de contextos, que sin embargo se ha considerado bien adaptado a la exigencia de abarcar la mayor extensión posible con intervenciones puntuales poco agresivas con el entorno habitado.

Se realizó un total de cinco sondeos, de los que uno, el sondeo AIZ/3 (coordenadas: X 562933.331 m; Y 4787186.476 m; Z 224.951 m) (fig. 2), reveló la existencia de un nivel de ocupación compuesto por fragmentos de carbón y arcilla rubefactada a un metro de profundidad. Ante esta evidencia, se decidió realizar una serie de pruebas físicas y químicas que permitieran caracterizar en detalle la estratigrafía del sondeo, para lo cual este fue debidamente sellado, rotulado y guardado en una cámara frigorífica a $3-4{ }^{\circ} \mathrm{C}$ hasta su apertura en el laboratorio.

\subsubsection{Caracterización estratigráfica}

La estratigrafía del sondeo se determinó mediante la combinación de distintos indicadores físico-químicos, tal y como se detalla a continuación. Los análisis se llevaron a cabo en el laboratorio CORELAB de la Universitat de Barcelona.

\section{FLUORESCENCIA DE RAYOS-X}

La preparación de la muestra consistió en el corte y apertura longitudinal del sondeo. Se realizaron mediciones de fluorescencia de rayos-X (XRF-CS) para determinar la composición elemental del registro a in- tervalos de $1 \mathrm{~cm}$, usando para ello un escáner de fluorescencia de rayos-X (XRF-CS) de la marca Avaatech. Este es un método no destructivo y semicuantitativo; no se obtiene la cantidad absoluta de los elementos en la muestra, pero sí la proporción de cada elemento medido respecto a los otros, mediante la diferencia de cuentas (cps) obtenidas para cada uno de ellos. El objetivo consistió, por tanto, en determinar la variabilidad de la concentración de los distintos elementos químicos a lo largo del registro sedimentario, con el fin de definir las unidades estratigráficas presentes en el mismo e identificar los procesos ambientales y antrópicos que habían contribuido a su formación.

Se trata de un indicador utilizado habitualmente en el estudio de registros sedimentarios obtenidos a través de sondeos manuales y mecánicos (p. ej. Abel-Schaad et al. 2018), por lo que su análisis se halla en gran medida estandarizado. La primera medición se realizó usando una corriente de rayos- $X$ de $500 \mu \mathrm{A}$, con un tiempo de medición de $10 \mathrm{~s}$ y un voltaje de rayos-X de $10 \mathrm{kV}$, se obtuvo la medida de los siguientes elementos: Al, $\mathrm{Si}, \mathrm{P}, \mathrm{S}, \mathrm{Cl}, \mathrm{Ar}, \mathrm{K}, \mathrm{Ca}, \mathrm{Ti}, \mathrm{V}, \mathrm{Rh}, \mathrm{Cr}, \mathrm{Mn}, \mathrm{Ag}$ y Fe. En un segundo momento, se repitió la medición con una corriente de rayos- $X$ de $1000 \mu \mathrm{A}$, un tiempo de medición de 25 s y un voltaje de $30 \mathrm{kV}$, además de un filtro $\mathrm{Pd}$, que proporcionó la medida del Ni, Cu, Zn, Ga, Ge, As, $\mathrm{Br}, \mathrm{Rb}, \mathrm{Sr}, \mathrm{Y}, \mathrm{Zr}, \mathrm{Nb}, \mathrm{Au}$ y $\mathrm{Pb}$.

Los datos geoquímicos obtenidos de ambas mediciones fueron filtrados y analizados mediante métodos de estadística multivariante, en particular mediante un análisis de componentes principales (ACP: Hotelling 1933), usando el programa SPSS 20.0. Esta técnica permitió reducir el número de variables obtenidas del análisis de XRF a una serie de factores principales que son una combinación lineal de las variables originales, independientes entre sí, a partir de las cuales es posible reconocer e interpretar los distintos procesos ambientales y antrópicos que explican la variabilidad presente en los resultados analíticos.

Sondeo AIZ16/3

$100 \mathrm{~cm}$

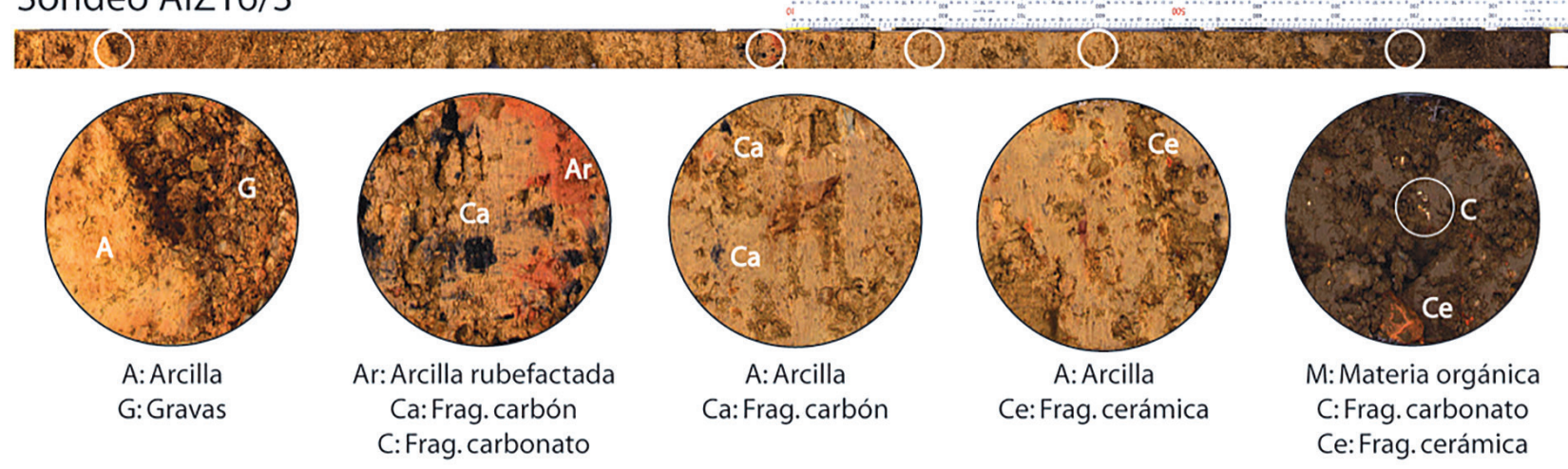

Fig. 2. Vista general y detalles del sondeo AIZ/3, donde puede apreciarse la presencia de los elementos descritos en el texto. El techo del sondeo está en el extremo derecho. / General view and details of the core sample AIZ/3, where the presence of the different elements discussed in the text can be observed. The top of the sequence corresponds to the right of the image. 
ANÁLISIS DE SUSCEPTIBILIDAD MAGNÉTICA

Adicionalmente, el sondeo fue sometido a un análisis de susceptibilidad magnética (MSCL), un indicador de carácter físico que permite identificar la presencia de minerales ferrimagnéticos en el seno del sedimento. Para ello se usó un sensor de puntero modelo Bartington MS2E montado sobre una plataforma multisensor GEOTEK. La medida se realizó a intervalos de 0,5 cm y los resultados fueron confrontados con los del XRF-CS con el fin de afinar la lectura estratigráfica del registro.

\subsubsection{Análisis antracológico}

Por otra parte, los abundantes restos antracológicos recuperados en el nivel identificado como de ocupación (1 m) fueron analizados en el Laboratorio de Paleobotánica Lydia Zapata, de la Universidad del País Vasco, con el objetivo de determinar su especie y características. Tanto para la metodología de muestreo como para el análisis taxonómico se emplearon los criterios de Chabal (1994; 1997), Chabal et al. (1999) y Figueiral \& Mosbrugger (2000). Para el análisis fueron seleccionados aleatoriamente carbones entre los fragmentos de tamaño entre los 2 y $4 \mathrm{~mm}$ y superiores a los $4 \mathrm{~mm}$.

El número máximo de análisis fue fijado según el principio estadístico de la curva de esfuerzo/rendimiento (Chabal 1982; 1988; 1997). Los carbones fueron seccionados en tres planos fundamentales: transversal, tangencial y radial. Las identificaciones taxonómicas se realizaron con un microscopio de luz incidente con 100x, 200x, 400x y 500x aumentos y empleando una colección de referencia de madera, así como los atlas de anatomía de la madera (Greguss 1955; Schweingruber 1990; Vernet et al. 2001). De cada fragmento de carbón se observó también el grado de curvatura de los anillos de crecimiento, con el fin de obtener un indicador del calibre de los fragmentos (Marguerie \& Hunnot 2007).

\subsubsection{Datación radiocarbónica}

Una vez establecida la estratigrafía del depósito recogido mediante los métodos arriba descritos, se procedió a fijar la cronología de los materiales provenientes de los distintos niveles identificados en el seno de la secuencia estratigráfica obtenida. Los fragmentos de carbón seleccionados en dichos niveles fueron enviados a la Università degli Studi della Campania 'Luigi Vanvitelli', para su tratamiento y datación por radiocarbono.

\subsection{Segunda intervención: excavación arqueológica}

Los resultados obtenidos de la primera intervención, con la existencia de un nivel de ocupación localizado bajo el relleno de la terraza, aconsejaban proceder a una segunda intervención, de carácter más intensivo, en octubre de 2017. Para ello, se realizó una pequeña excavación arqueológica de 2x2 m de superficie, posteriormente ampliado a $3 \times 3 \mathrm{~m}$ (sector ETK1000) ante la dificultad de interpretar los restos documentados. Los objetivos fueron principalmente dos: 1) ampliar la documentación de la secuencia estratigráfica del área de estudio; y 2) caracterizar las fases de ocupación presentes en el mismo, recabando material arqueológico y poniéndolo en relación con las dataciones obtenidas. Y aunque está prevista la realización de otras excavaciones, los resultados obtenidos son ya significativos.

\section{RESULTADOS}

\subsection{Secuencia quimioestratigráfica}

Las variaciones en la composición elemental del registro sedimentario recogido en el sondeo $\mathrm{AlZ} / 3$ se sintetizan en seis componentes principales o PC (fig. 2, tabla I), que explican el $84,8 \%$ de la varianza total.

El CP1 es el más representativo de estos factores, explica el 29,9\% de la varianza total. Este componente refleja una relación inversa entre los valores de $\mathrm{Pb}$, $\mathrm{Zn}, \mathrm{Ca}, \mathrm{P}, \mathrm{Br}$ (correlación positiva superior a 0,7 ) y $\mathrm{Sr}$ (correlación positiva moderada, ca. 0,6), por un lado; y As (correlación negativa alta), por otro. Pb, Zn y P suelen ser elementos biófilos, asociados a la presencia de materia orgánica (Krosshavn et al., 1993; Chen et al., 2018), cuya considerable concentración en algunos puntos del registro podría relacionarse con aportes antrópicos de distintos elementos de origen animal y vegetal. De la misma manera, las concentraciones de $\mathrm{Br}$ podrían estar relacionadas con la presencia de materia orgánica vegetal y con procesos de halogenación y deshalogenación de la misma en los suelos (Van Pée \& Unversuch 2003; Biester et al. 2006; Leri \& Myneni 2012). Por su parte, la presencia de Ca podría deberse a sedimentos terrígenos carbonatados ( $\mathrm{CaCO} 3)$ derivados del sustrato cretácico presente en el entorno, aunque las significativas concentraciones registradas en determinados puntos (figs. 2, 3) sugieren la existencia de aportes de origen antrópico (cal).

El CP2 explica el 27,9\% de la varianza total, con altas correlaciones positivas para Ti, Si, Zr, Al, K, V y Rb. Estos elementos litogénicos son indicativos del contenido en minerales siliciclásticos de grano fino, como arcillas y cuarzo, presentes en el sedimento fluviokárstico plio-cuaternario que rellena las depresiones kársticas de los alrededores. Las variaciones en el contenido de la fracción mineral (fig. 3, tabla I) indican que la cantidad relativa de minerales de arcilla varía en relación a la presencia, también variable, de otros componentes sedimentarios, como la fracción orgánica u otros aportes antrópicos como la cal, detectados en el componente anterior.

El CP3 explica el 9,2\% de la varianza total, y aparece controlado por las altas correlaciones positivas de Co y Fe. Finalmente, el CP4, el CP5 y el CP6 explican 
el $6,8 \%$, el $6,2 \%$ y el $5 \%$ respectivamente de la varianza total. Todos ellos son poco significativos, dado que incluyen solo uno o dos elementos, con cuentas relati- vamente bajas en el análisis de XRF-CS y altas correlaciones positivas: $\mathrm{Mn}$ y $\mathrm{Cr}$ en el caso del CP4, Y en el $\mathrm{CP} 5$ y $\mathrm{Cl}$ en el CP6.

\begin{tabular}{|c|c|c|c|c|c|}
\hline CP1 & CP2 & CP3 & CP4 & CP5 & CP6 \\
\hline 0,942209043 & $-0,241843048$ & $-0,037912258$ & 0,133102875 & $-0,000973113$ & $-0,082228677$ \\
\hline 0,940769892 & $-0,184203304$ & $-0,106544411$ & 0,124604767 & $-0,051879548$ & $-0,095831378$ \\
\hline 0,933132693 & $-0,194951547$ & $-0,074252478$ & $-0,074468009$ & 0,146432124 & 0,001537165 \\
\hline 0,932104035 & $-0,077899738$ & 0,061284518 & $-0,118221244$ & $-0,188493888$ & $-0,04159618$ \\
\hline 0,783656233 & $-0,05849754$ & 0,107127003 & $-0,425584863$ & 0,101782569 & 0,065603833 \\
\hline 0,714244241 & $-0,322606695$ & $-0,225578452$ & $-0,017873831$ & $-0,287253483$ & 0,171795403 \\
\hline 0,685670417 & $-0,067547166$ & $-0,186474608$ & 0,454071475 & 0,421350899 & $-0,084716889$ \\
\hline 0,079219651 & $-0,267140754$ & 0,32071095 & 0,665501938 & 0,251800664 & $-0,027418655$ \\
\hline$-0,013421782$ & 0,063268381 & $-0,082257339$ & 0,059342116 & 0,087993581 & 0,937527916 \\
\hline$-0,032091608$ & 0,388422487 & 0,828485858 & 0,082209187 & 0,041415282 & $-0,080352353$ \\
\hline$-0,064910471$ & 0,881445488 & $-0,017899482$ & $-0,063112713$ & 0,125296069 & 0,022505654 \\
\hline$-0,119131289$ & 0,93952881 & 0,210395026 & $-0,001311296$ & 0,067710074 & 0,03215145 \\
\hline$-0,135349535$ & 0,253269022 & 0,005673378 & 0,037620785 & 0,884511262 & 0,105327576 \\
\hline$-0,14527344$ & 0,928993065 & 0,248752512 & $-0,133497842$ & 0,009460681 & 0,067773024 \\
\hline$-0,231931821$ & 0,362759098 & 0,813258719 & 0,239612752 & $-0,064618836$ & $-0,025895786$ \\
\hline$-0,23465031$ & 0,741557411 & $-0,214339139$ & 0,39083214 & $-0,190977015$ & $-0,15685716$ \\
\hline$-0,240156374$ & 0,844972257 & 0,344688856 & $-0,041053164$ & 0,038346446 & 0,034794981 \\
\hline$-0,261061769$ & 0,78023869 & 0,14969432 & $-0,075656846$ & 0,153379346 & 0,038162289 \\
\hline$-0,307678799$ & 0,865901028 & 0,27682875 & $-0,016387911$ & 0,088834424 & 0,074735523 \\
\hline$-0,346069692$ & 0,082635375 & 0,183811032 & 0,565668252 & $-0,171106271$ & 0,301060911 \\
\hline$-0,545378912$ & 0,496822972 & 0,09536206 & 0,160323008 & 0,196027892 & $-0,126843907$ \\
\hline$-0,80606407$ & 0,244330091 & 0,160391551 & 0,119758874 & 0,076436307 & 0,022356957 \\
\hline
\end{tabular}

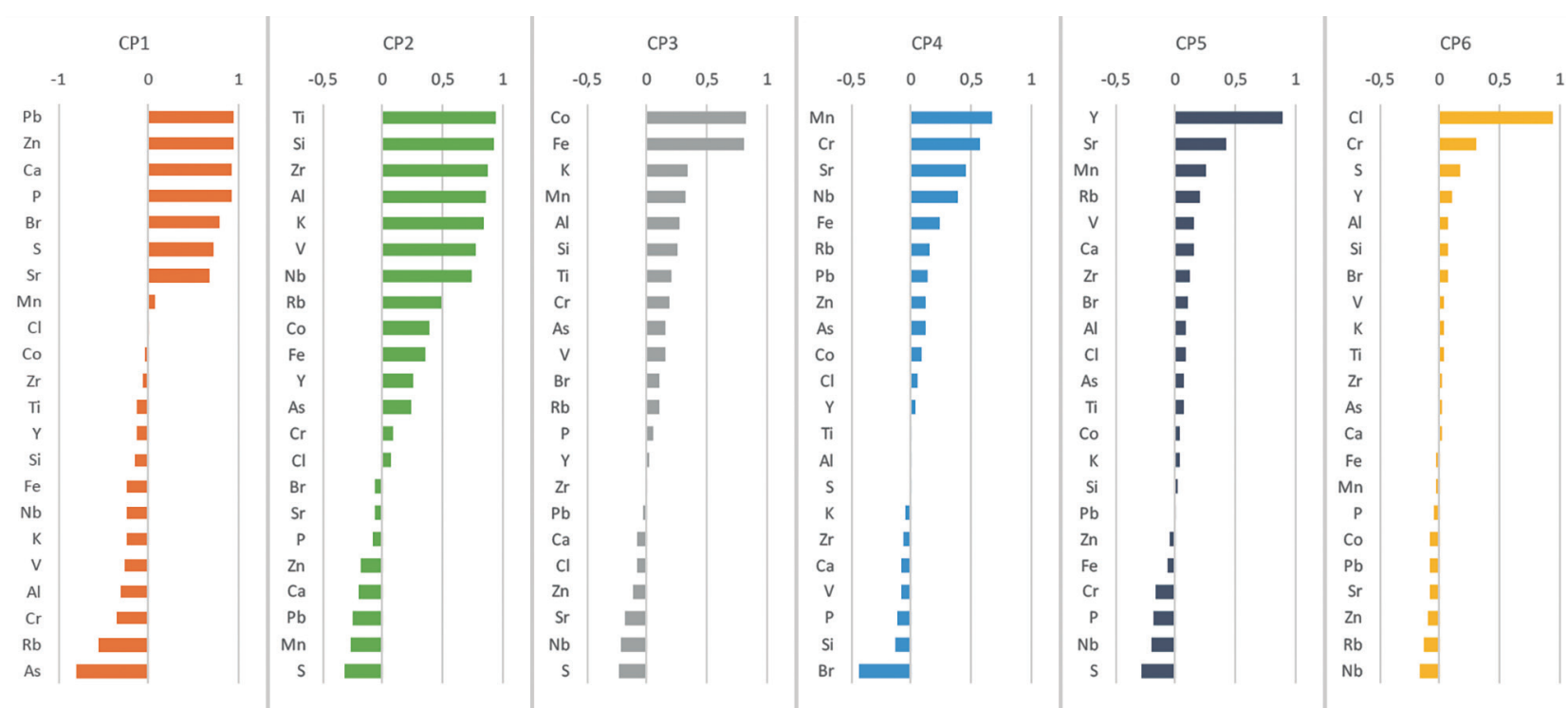

Tabla 1: Matriz de correlación e histogramas entre los elementos analizados y los componentes principales obtenidos del análisis de PCA. Los elementos con correlaciones altas y moderadas con los distintos componentes principales se han resaltado mediante negrita / Loading factors and histograms of the analysed elements and the principal components obtained from PCA. The elements showing high and moderate loading factors in the different principal components have been highlighted in bold. 


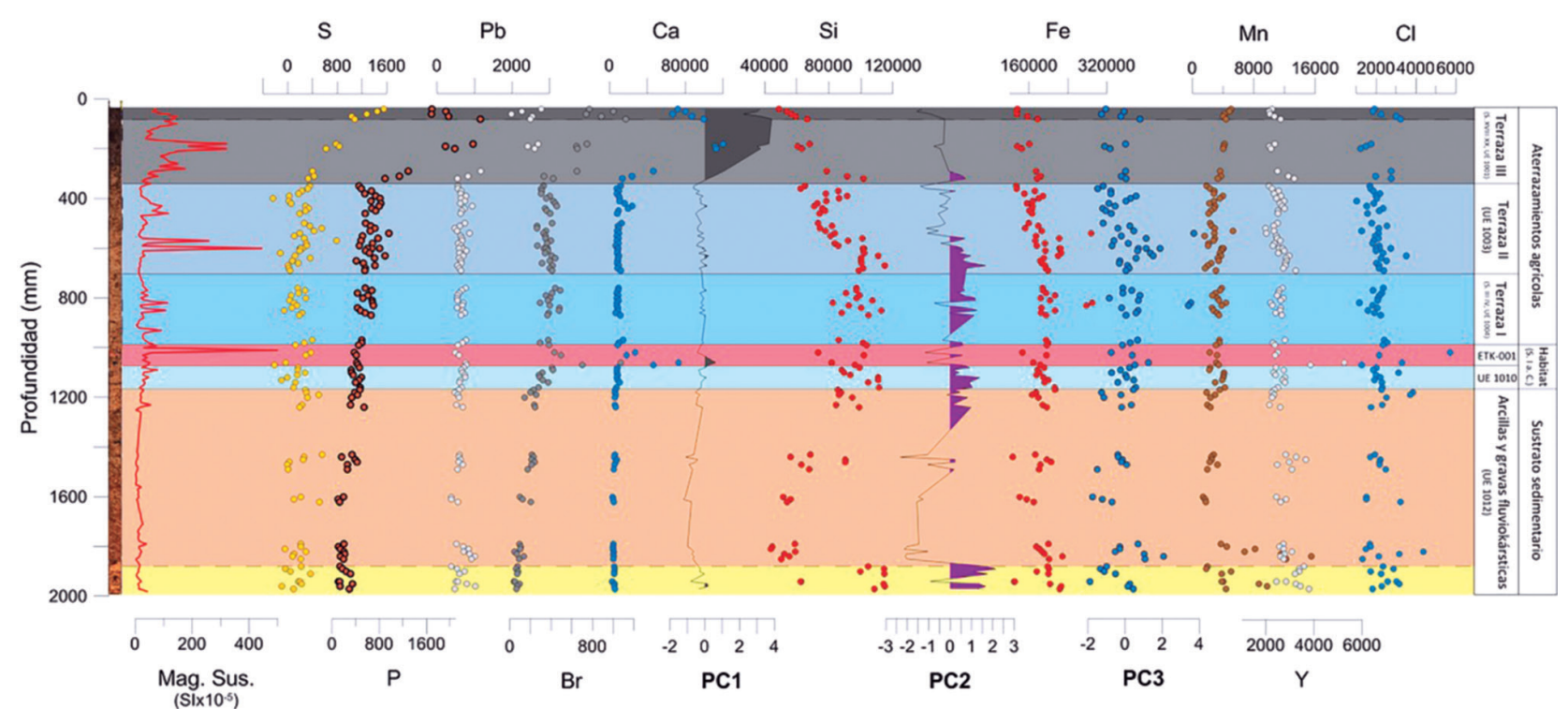

Fig. 3. Síntesis e interpretación estratigráfica de los resultados de XRF-CS y susceptibilidad magnética en el sondeo AIZ/3./ Synthesis and stratigraphic interpretation of the results of XRF-CS and magnetic susceptibility in the core sample AIZ/3.

\subsection{Susceptibilidad magnética}

La susceptibilidad magnética (SM) en suelos y sedimentos está relacionada con la presencia y/o neoformación de minerales ferrimagnéticos. Estos minerales pueden estar presentes debido a distintos procesos, y sus valores de susceptibilidad magnética dependen de la concentración de Fe disponible en el sedimento original, del tipo de mineral ferromagnético presente y de su tamaño de grano. En el caso del sondeo AIZ/3, el sedimento arcilloso fluviokárstico basal presenta valores de SM muy por debajo $\left(<100 \mathrm{SI} \times 10^{-5}\right)$ del de las unidades con valores más elevados (entre 200 y $800 \mathrm{SI} \times 10^{-5}$ ) (fig. 2). La práctica totalidad de los picos de SM detectados obedecen a la presencia de: 1) fragmentos cerámicos (tejas) usados como abono y relleno de las zonas de cultivo; 2) sedimentos o agregados arcillosos rubefactados, que se relacionan con episodios de combustión.

\subsection{Excavación arqueológica}

\subsubsection{Estratigrafía}

La estratigrafía de la excavación arqueológica resulta plenamente coherente con la obtenida del análisis de XRF y MSCL del sondeo AIZ/3 (fig. 4). El sedimento fluviokárstico plio-cuaternario infrayacente (UE 1012) aparece a una profundidad de entre 100 y $120 \mathrm{~cm}$, y sobre este las UUEE 1009 y 1010, con huellas de frecuentación humana, como la presencia de materiales cerámicos. Sobre estos, se localizaron los restos de una estructura ETK-01, compuesta por grandes fragmentos de madera carbonizada de hasta 30x40 cm (UUEE 1011, 1013, 1008, 1005) y arcilla rubefactada por la acción del fuego (UE 1006), que fue excavada en su tercio septentrional mostrando una potencia de en torno a $15 \mathrm{~cm}$ (figura 5). Estos restos se hallaban cubiertos por un nivel de

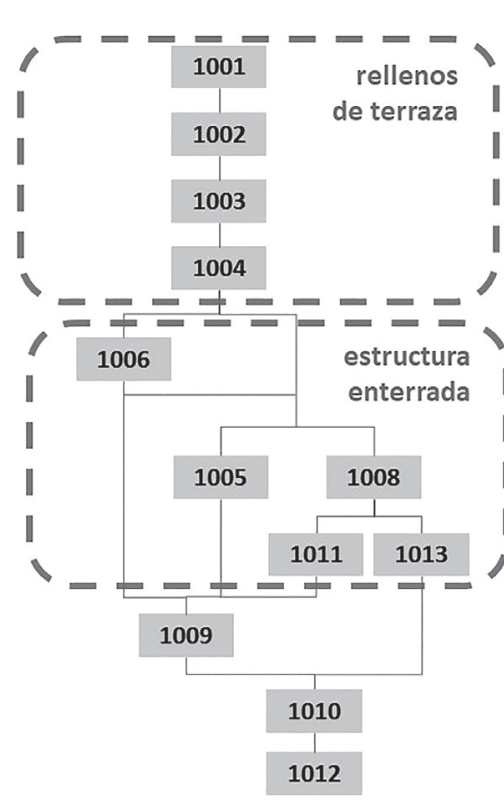

Fig. 4. Matriz de Harris que representa la secuencia estratigráfica de la excavación arqueológica./ Harris' matrix showing the stratigraphic sequence of the archaeological excavation

arrastre con abundante material constructivo y lítico (UE 1004), que a su vez había sido sellado por un relleno de aterrazamiento (UE 1003). Una clara interfaz ondulada (UE 1002) dividía este último depósito de la superficie de arado suprayacente (UE 1001).

\subsubsection{Dataciones}

Las dataciones por radiocarbono se practicaron en los niveles asociados directamente con la estructura ETK-01 o su amortización. En primer lugar, se dató un fragmento de carbón de la UE 1004, perteneciente al género Alnus, que proporcionó una edad convencional 


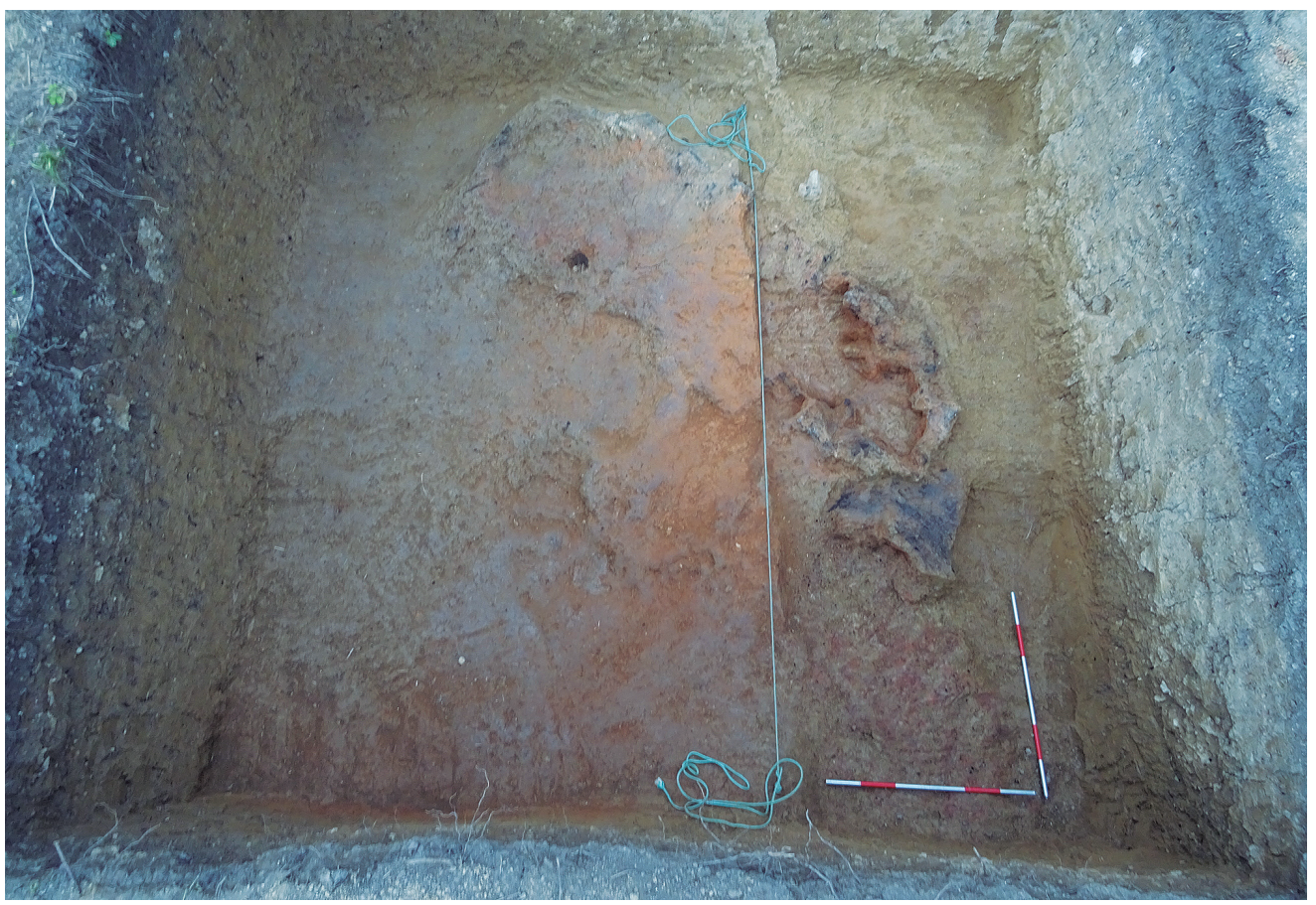

Fig. 5. Vista general de la excavación arqueológica. El tercio norte (a la derecha de la imagen) muestra la estructura de madera carbonizada ETK-01 expuesta sobre la UE 1010. El resto del sector muestra la UE 1006, compuesta por arcilla termoalterada (rubefactada) cubriendo la estructura ETK-01./ General view of the archaeological excavation. The northern sector (at the right of the image) shows the carbonised wooden structure ETK-01 displayed above the SU 1010. The rest of the sector shows the UE 1006, composed of thermoalterated (rubefacted) clay covering the structure ETK-01.

de radiocarbono de $1781 \pm 37 \mathrm{BP}^{4}$. Este carbón se hallaba incluido en un depósito sedimentario, por lo que la fecha obtenida constituye una referencia postquem del momento de deposición de este. En segundo lugar, se dató otro fragmento de carbón de la UE 1005, del género Quercus, que arrojó una edad convencional de radiocarbono de 2019 $\pm 39 \mathrm{BP}^{5}$. Esta última fecha marca la edad de muerte del árbol, que por lo tanto constituye un momento probablemente poco anterior a construcción de la estructura (UUEE 1005, 1008, 1011 y 1013).

\subsubsection{Materiales arqueológicos}

CARBÓN

Las UUEE 1005, 1008, 1011 y 1013, todas ellas asociadas a la estructura ETK-01, se hallaban formadas por fragmentos de madera carbonizada de diferentes tamaños, algunos de los cuales presentaban cortes rectilíneos que permiten identificarlos como materiales claramente antrópicos y asociados a una posible estructura arquitectónica (pared o techo). Una muestra representativa de estos materiales fue recuperada del sondeo geoarqueológico AIZ/3, cuyo estudio antracológico permitió la identificación de 22 fragmentos, todos pertenecientes al género Quercus de tipo caducifolio (Tabla II). 3 fragmentos no pudieron ser identificados debido a su alto grado de vitrificación o deformación.
Debido a una buena visibilidad de la sección transversal, en 4 fragmentos fue posible registrar el grado de curvatura de los anillos. Todos estos fragmentos presentan curvatura débil, lo cual indica que pertenecen a fragmentos de madera de cierto calibre. Por otra parte, solo en los fragmentos que superan los $4 \mathrm{~mm}$ fue posible observar la presencia/ausencia de tílides e hifas. Entre estos, el $67 \%$ presenta tílides y el 100\% no está afectado por hifas.

\section{Cerámica}

Los materiales cerámicos recuperados en el curso de la excavación se recogen en la Tabla III. Se trata de un total de 113 fragmentos, que pueden dividirse en dos grandes conjuntos. Por un lado, los materiales aparecidos en la UE 1001, asociados, por tanto, a las fases más recientes del yacimiento. Los materiales provenientes de este nivel forman el conjunto más numeroso, con 79 fragmentos correspondientes en su totalidad a cronologías postmedievales.

Por otro lado, se encuentran los materiales aparecidos debajo del relleno de terraza UE 1003, relacionados con los niveles contemporáneos a la estructura ETK-01 o bien con la erosión de estos. Son un total de 34 fragmentos, guardan una notable coherencia en cuanto a sus características, puesto que se trata casi en su totali-

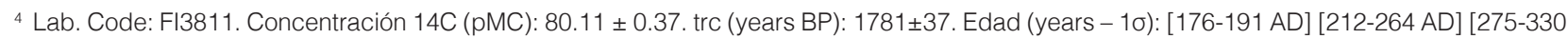
$A D]$. Edad (years - 20): [131-344 AD].

${ }^{5}$ Lab. Code: Fi3493. Concentración 14C (pMC): 77,78 \pm 0,38. trc (years BP): $2019 \pm 39$. Edad (years - 1б): [55BC-29AD] [86-80BC]. Edad
} (years - 2б): [115BC-67AD] [157-135BC]. 


\begin{tabular}{|c|c|c|c|c|c|c|c|c|}
\hline \multicolumn{9}{|c|}{ RESULTADOS DEL ANÁLISIS ANTRACOLÓGICO } \\
\hline Año & Año & Muestra & ø & $\#$ & Taxa & Curv. Anillos & Tílides & Hifas \\
\hline Aizarna & 2016 & $3.1 / 100$ & $4 \mathrm{~mm}$ & 1 & Quercus caducifolio & débil & no & no \\
\hline Aizarna & 2016 & $3.1 / 100$ & $4 \mathrm{~mm}$ & 2 & Quercus caducifolio & débil & si & no \\
\hline Aizarna & 2016 & $3.1 / 100$ & $4 \mathrm{~mm}$ & 3 & Quercus caducifolio & - & si & no \\
\hline Aizarna & 2016 & $3.1 / 100$ & $4 \mathrm{~mm}$ & 4 & Indeterminado & - & no & no \\
\hline Aizarna & 2016 & $3.1 / 100$ & $4 \mathrm{~mm}$ & 5 & Quercus caducifolio & débil & si & no \\
\hline Aizarna & 2016 & $3.1 / 100$ & $4 \mathrm{~mm}$ & 6 & Quercus caducifolio & débil & si & no \\
\hline Aizarna & 2016 & $3.1 / 100$ & $2 \mathrm{~mm}$ & 7 & Quercus caducifolio & - & - & - \\
\hline Aizarna & 2016 & $3.1 / 100$ & $2 \mathrm{~mm}$ & 8 & Quercus caducifolio & - & - & - \\
\hline Aizarna & 2016 & $3.1 / 100$ & $2 \mathrm{~mm}$ & 9 & Quercus caducifolio & - & - & - \\
\hline Aizarna & 2016 & $3.1 / 100$ & $2 \mathrm{~mm}$ & 10 & Quercus caducifolio & - & - & - \\
\hline Aizarna & 2016 & $3.1 / 100$ & $2 \mathrm{~mm}$ & 11 & & - & - & - \\
\hline Aizarna & 2016 & $3.1 / 100$ & $2 \mathrm{~mm}$ & 12 & Quercus caducifolio & - & - & - \\
\hline Aizarna & 2016 & $3.1 / 100$ & $2 \mathrm{~mm}$ & 13 & Quercus caducifolio & - & - & - \\
\hline Aizarna & 2016 & $3.1 / 100$ & $2 \mathrm{~mm}$ & 14 & Quercus caducifolio & - & - & - \\
\hline Aizarna & 2016 & $3.1 / 100$ & $2 \mathrm{~mm}$ & 15 & Quercus caducifolio & - & - & - \\
\hline Aizarna & 2016 & $3.1 / 100$ & $2 \mathrm{~mm}$ & 16 & Quercus caducifolio & - & - & - \\
\hline Aizarna & 2016 & $3.1 / 100$ & $2 \mathrm{~mm}$ & 17 & Quercus caducifolio & - & - & - \\
\hline Aizarna & 2016 & $3.1 / 100$ & $2 \mathrm{~mm}$ & 18 & Quercus caducifolio & - & - & - \\
\hline Aizarna & 2016 & $3.1 / 100$ & $2 \mathrm{~mm}$ & 19 & Quercus caducifolio & - & - & - \\
\hline Aizarna & 2016 & $3.1 / 100$ & $2 \mathrm{~mm}$ & 20 & Indeterminado & - & - & - \\
\hline Aizarna & 2016 & $3.1 / 100$ & $2 \mathrm{~mm}$ & 21 & Quercus caducifolio & - & - & - \\
\hline Aizarna & 2016 & $3.1 / 100$ & $2 \mathrm{~mm}$ & 22 & Quercus caducifolio & - & - & - \\
\hline Aizarna & 2016 & $3.1 / 100$ & $2 \mathrm{~mm}$ & 23 & Quercus caducifolio & - & - & - \\
\hline Aizarna & 2016 & $3.1 / 100$ & $2 \mathrm{~mm}$ & 24 & Quercus caducifolio & - & - & - \\
\hline Aizarna & 2016 & $3.1 / 100$ & $2 \mathrm{~mm}$ & 25 & Quercus caducifolio & - & - & - \\
\hline
\end{tabular}

Tabla 2: Resultados del análisis antracológico. Por cada fragmento de carbón se especifica: tamaño de la malla de la criba de recuperación (ø); número de la muestra (\#); Taxa; grado de curvatura de los anillos (Curv. anillos) dividido en débil, moderado y fuerte; presencia/ausencia de tílides escleróticas (Tílides) y presencia/ausencia de hifas (Hifas). / Results of the anthracological analysis. The following data are specified for each fragment: size of the mesh used for sieving (ø); number of the sample (\#); Taxa; degree of ring curvature (Curv. anillos) divided into weak, moderate and strong; presence/absence of sclerotic tyloses (Tilides); and presence/absence of hyphae (Hifas).

\begin{tabular}{|c|c|c|c|c|c|c|c|c|}
\hline UE & Tipo & Asas & Cuerpos & Bordes & Fondos & Total & Edad aprox. & Referencia \\
\hline \multirow{7}{*}{1001} & Esmaltada & 2 & 20 & 4 & & 26 & $X V I I-X V I I I$ & Salsamendi 2007 \\
\hline & Esmaltada dec. & & 2 & 1 & & 3 & $X V I I-X V I I I$ & Salsamendi 2007 \\
\hline & Esmaltada/vidriada & & 4 & & & 4 & $X V I I-X V I I I$ & Salsamendi 2007 \\
\hline & Vidriada & & 8 & 2 & 2 & 12 & $X V I I-X V I I I$ & Salsamendi 2007 \\
\hline & Sin revestir & & 4 & 1 & & 5 & h. XIII & Salsamendi 2007 \\
\hline & Creamware & 1 & 11 & 11 & 3 & 26 & $X I X$ & Salsamendi 2007 \\
\hline & Porcelana & & 1 & 1 & 1 & 3 & XVIII-XIX & Salsamendi 2007 \\
\hline 1004 & Común romana & & 8 & & & 8 & I-IV & Martínez 2004 \\
\hline 1009 & Indeterminada & & 1 & & & 1 & $?$ & \\
\hline \multirow{2}{*}{1010} & Común romana & & 23 & & & 23 & I-IV & Martínez 2004 \\
\hline & Común romana & & 1 & 1 & & 2 & I-IV & Martínez 2004 \\
\hline
\end{tabular}

Tabla 3: Tabla resumen del número y características principales de los materiales cerámicos recuperados. / Summarised table of the number and characteristic of the recovered ceramic materials. 
dad de cerámica común no torneada, de cocción mixta y desgrasantes angulosos de tamaño medio.

- UE 1010. Este depósito ha proporcionado el fragmento más diagnóstico (fig. 6a). Se trata de un borde vuelto al exterior con labio plano, perteneciente a una olla de cocina del tipo 701 según las clasificaciones de Esteban et al. (2000) y Martínez Salcedo (2004b), o CCTA I según Amondarain (2017). Este tipo de producciones de cerámica común, halladas por todo el Cantábrico, valle del Ebro y Aquitania, se fechan sobre todo en época altoimperial (ss. I-II d.C.), aunque pueden prolongarse hasta época tardoantigua (ss. IV-V d.C.). Se trata, por tanto, de materiales coherentes con la datación radiocarbónica obtenida.

- UE 1009. Se ha recogido un total de 23 fragmentos, todos ellos paredes, cuyo pequeño tamaño y precaria conservación dificultan identificar las formas a las que pertenecen (fig. 6b-c). En cualquier caso, se trata de producciones similares a las anteriores, realizadas a torno rápido, con cocciones que varían desde la oxidante hasta la reductora - lo que se traduce en coloraciones que van del negro al rojo-y desgrasantes de tamaño medio-grande. Hay, finalmente, una pieza de cerámica depurada, muy degradada, cuya tipología no se ha podido determinar debido a su mala conservación; podría tratarse de una pieza de mesa, o bien de una sigillata que ha perdido el engobe.

- UE 1004. Este nivel ha proporcionado tres fragmentos más de cerámica, tipológicamente similares a los anteriores (fig. 6d). Aunque se hayan recogido en posición secundaria, por tanto, su procedencia podría asociarse con el entorno inmediato de la estructura.

Material Constructivo

Este apartado está compuesto por un conjunto de materiales localizados en la UE 1004. Se trata de un total de 4 piezas de adobe y 5 fragmentos de tejas y ladrillos. Todos estos materiales aparecieron en posición secundaria, bastante rodados y degradados, lo cual dificulta identificar tipología alguna.

\section{MATERIAL Lítico}

También se ha localizado una acumulación significativa de materiales líticos en la UE 1004: 5 fragmentos de piedra arenisca trabajada, 9 fragmentos de roca volcánica y 6 fragmentos de carbón mineral (lignito). Estos materiales y la unidad arcillosa que los comprende constituyen claramente un aporte de origen antrópico,

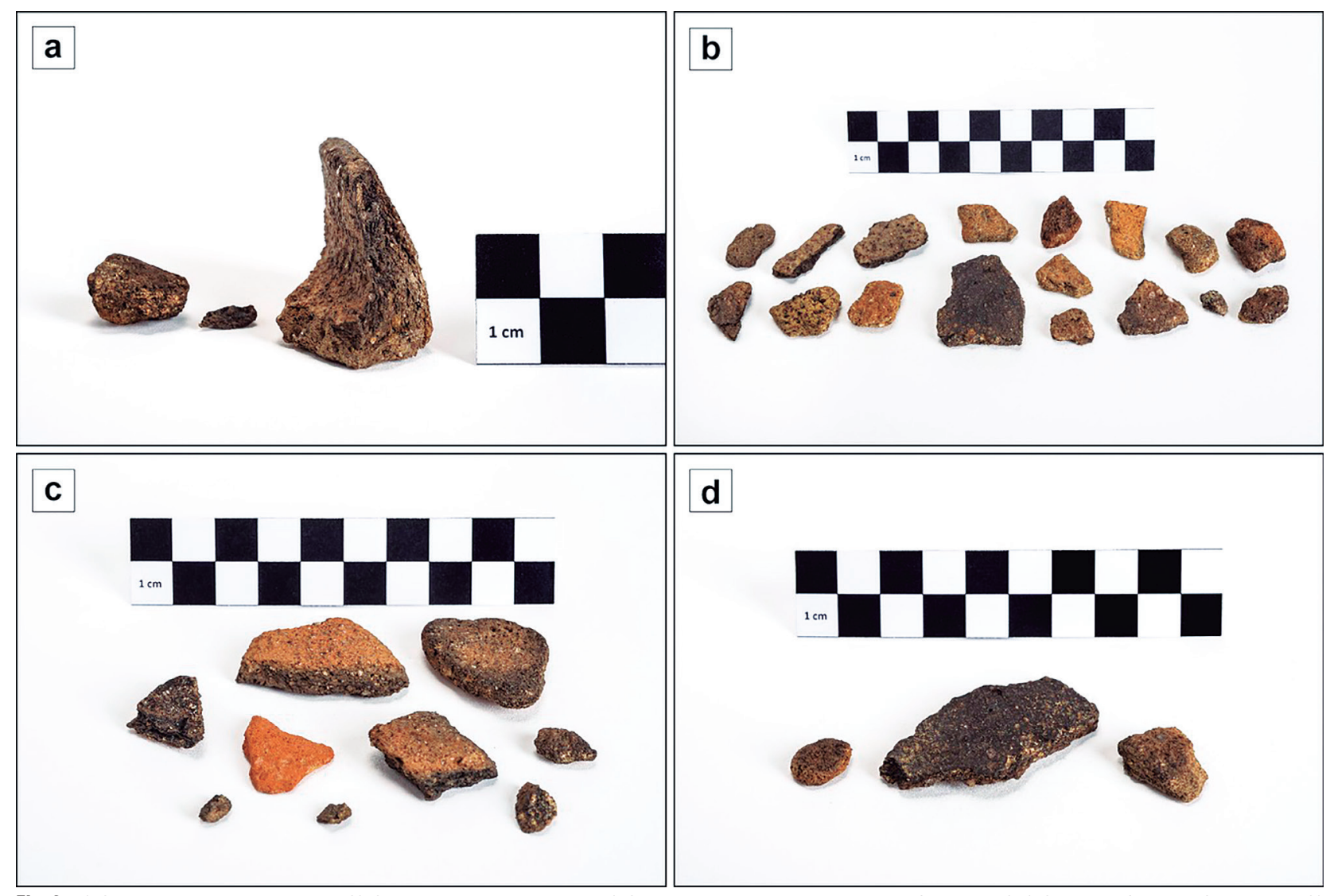

Fig. 6. A) Cerámicas de la UE 1010. B-C) Cerámicas de la UE 1009. D) Cerámicas de la UE 1004. Fotografía: Lamia./ A) Ceramics from the SU 1010. B-C) Ceramics from the SU 1009. D) Ceramics from the SU 1004. Images: Lamia. 
que engloba elementos arqueológicos en posición secundaria y, por tanto, degradados.

\section{ESCORIAS METÁLICAS}

La UE 1004 proporcionó, además, dos fragmentos de escorias metálicas, uno de hierro y otro de plomo. Ambos aparecieron rodados y en posición secundaria.

\section{ÓXIDOS E HIDRÓXIDOS DE HIERRO}

Finalmente, también en la UE 1004, se localizó una acumulación de distintos materiales metálicos, todos ellos igualmente arrastrados y rodados. Se trata, principalmente, de nódulos y agregados de óxidos e hidróxidos de hierro en distintas fases de oxidación, principalmente de hematites (21 fragmentos, $688 \mathrm{~g}$ ) y goethita (19 fragmentos, $508 \mathrm{~g}$ ), que tienen también su reflejo en las curvas de XRF en un aumento de la concentración de $\mathrm{Fe}$, incluso la presencia de picos, entre 60 y $90 \mathrm{~cm}$ de profundidad (fig. 3).

\section{INTERPRETACIÓN: LA FORMACIÓN DEL RE- GISTRO ARQUEOLÓGICO}

El análisis combinado de la secuencia quimioestratigráfica del sondeo, así como de la estructura identificada y los materiales recuperados en el curso de la excavación, permite reconstruir con cierto nivel de detalle el proceso de formación del registro arqueológico de Erretorekoa, articulado en cuatro fases ocupacionales que se discuten a continuación.

\section{FASE 1. Sustrato SEDIMENTARIO}

La UE 1012, compuesta por arcillas y gravas centimétricas que se encuentran a unos $120 \mathrm{~cm}$ de profundidad, fue identificada como parte del sustrato sedimentario, compuesto por depósitos fluviokársticos plio-cuaternarios similares a los presentes en distintos rellenos de la depresión kárstica de Aizarna. Debe tenerse en cuenta que nos hallamos a pocos metros de uno de los principales sumideros de toda la cuenca hidrológica circundante, la dolina de Zuloeta, por lo que se trata de una zona de erosión, con una pendiente natural significativa que actualmente aparece mitigada por la construcción de numerosas terrazas y canales.

\section{FASE 2. OCUPACIÓN DE ÉPOCA ANTIGUA}

Sobre la UE 1012 se dispone el estrato UE 1010, de carácter menos compacto y homogéneo. Se trata de un nivel de frecuentación humana, en el que el sedimento natural aparece alterado por la presencia de aportes sedimentarios adicionales (p. ej. carbón). Esto se traduce, en el análisis de la composición química, en un ligero aumento en la concentración de determinados elementos asociados a la presencia de materia orgánica (Pb, S, Br y PC1), así como por la presencia de material arqueológico (un fragmento de cerámica común romana).

Este depósito se encuentra estratigráficamente debajo de la estructura ETK-01, localizada a entre 90 y 110 $\mathrm{cm}$ de profundidad. Dicha estructura se compone de varios fragmentos de madera carbonizada apoyados directamente sobre la UE 1010, formando un derrumbe. La base de esta acumulación de carbones está formada por las UUEE 1011 y 1013; en ambos casos, se trata de impresiones de escaso grosor $(0,5 \mathrm{~cm})$ dejadas por piezas de madera de gran tamaño, posiblemente tablas. En cualquier caso, sobre ellas se apoya un grupo de fragmentos de carbón (UE 1008) estratigráficamente equivalentes a los que componen la UE 1005, al suroeste del sector. Estos carbones pertenecen en su mayoría a madera de roble de gran calibre y de cierta madurez. Se trata, probablemente, de restos de postes, vigas u otros elementos arquitectónicos importantes, lo que no sorprendería dado que la madera de roble, resistente, aunque poco elástica, fue (y sigue siendo) particularmente apta para ser empleada como material de construcción (López González 1982; Schofield 1991; Vignote Peña et al. 2000; Abella 2013). Por otra parte, el análisis de XRF muestra una alta concentración de Ca y $\mathrm{Br}$ a una profundidad de $105 \mathrm{~cm}$, es decir, en la base de la acumulación de carbones que se ha interpretado como el derrumbe de la estructura ETK-01 (fig. 3). Teniendo en cuenta las características geomorfológicas del entorno, estas medidas solo pueden corresponder a un aporte de origen antrópico, seguramente a un delgado y erosionado suelo de cal (recarbonatada, CaCO3) y carbón leñoso derivado de la concentración de madera quemada (alto contenido en $\mathrm{Br}$ ).

En cualquier caso, estos carbones se hallan en su mayor parte incluidos en un delgado $(<2 \mathrm{~cm})$ estrato de arcilla rubefactada (UE 1006), como consecuencia del fuego, bien intencionado o bien fortuito, que quemó la estructura, probablemente, en torno a la segunda mitad del siglo I a.C. La combustión debió ser localizada e intensa, dada la señal de susceptibilidad magnética de este nivel arcilloso, que, a diferencia del superior y el subyacente, refleja un pico acentuado en las medidas $\left(400 \mathrm{SI} \times 10^{-5}\right)$, debido a la formación de minerales ferromagnéticos como consecuencia de la termoalteración del sedimento en torno a la estructura quemada. El nivel arcilloso rubefactado podría corresponder a un recubrimiento de arcilla exterior de una pared o techo con entramado de madera, colapsada y quemada.

Así, si bien la arquitectura en madera y las paredes con recubrimientos de arcilla no son desconocidas en el País Vasco para estas cronologías (Cepeda 2001; Hidalgo 2014), estos elementos solo se han documentado allí donde la acción del fuego ha permitido su preservación, puesto que en condiciones normales se trata de materiales perecederos que dejan una señal muy tenue en el registro arqueológico. 
En definitiva, nos encontramos muy probablemente ante los restos de una estructura arquitectónica en madera, de época altoimperial, que las características de la fábrica y los materiales cerámicos asociados inducen a caracterizar como doméstica

\section{FASE 3. EROSIÓN Y AMORTIZACIÓN}

Una vez quemada, la estructura ETK-01 quedó a la intemperie y fue erosionada por la escorrentía superficial, tal y como muestran las abundantes inclusiones de carbón y arcilla rubefactada en toda la UE 1009, que se extiende ladera abajo en todo el lado suroriental de la excavación (fig. 7). Estos restos, originarios de la estructura, deben considerarse arrastrados por el agua y la gravedad a lo largo del tiempo en el que esta estuvo expuesta, y forman, por tanto, parte de los procesos postdeposicionales que cabría esperar teniendo en cuenta la situación en ladera del yacimiento y la dinámica geomorfológica del entorno.

En este sentido, la presencia de numerosos fragmentos de cerámica de cocina romana en este nivel, extremadamente fragmentados y rodados, se explicaría por su proveniencia de niveles de frecuentación antiguos situados en el entorno, ya sea de la estructura ETK01 o bien del área inmediatamente superior. Esto implica que la estructura excavada no se encontraba aislada, sino que formaba parte de un asentamiento más grande, situado en el espacio actualmente ocupado por la casa rectoral, la iglesia parroquial y la plaza de Aizarna.
Finalmente, toda esta fase de ocupación y posterior erosión aparece amortizada por la UE 1004, un nivel de aterrazamiento formado como consecuencia de procesos sedimentarios naturales o bien por un aporte antrópico intencional. En cualquier caso, el relleno incluye numerosos materiales constructivos, líticos y metálicos (incluyendo mineral de hierro y escorias). Debido a su posición secundaria, estos materiales aparecen rodados y generalmente muy degradados, por lo que resulta muy difícil caracterizarlos. En cualquier caso, la datación radiocarbónica practicada en una muestra de carbón proveniente de esta UE sugiere que dichos materiales, provenientes de niveles antiguos erosionados de cotas más altas, fueron depositados probablemente a finales del siglo III o principios del IV d.C.

\section{Fase 4. Relleno agrario}

La UE 1003 implica un aporte de tierra de dimensiones considerables, sobre todo en contraste con las parcelas circundantes, situadas a cota muy inferior. El estrato, con un carácter marcadamente más orgánico que los niveles inferiores, presenta muy poco material arqueológico, lo cual hace pensar en un solo episodio de relleno. Sobre este, la agricultura se habría llevado a cabo en los 30-40 cm superiores, profundidad a la que llegaría el arado, tal y como evidencia la UE 1002. Por encima de ese nivel, la actividad agraria habría ido mezclando continuamente la misma tierra (UE 1001), contribuyendo a la formación de un palimpsesto que

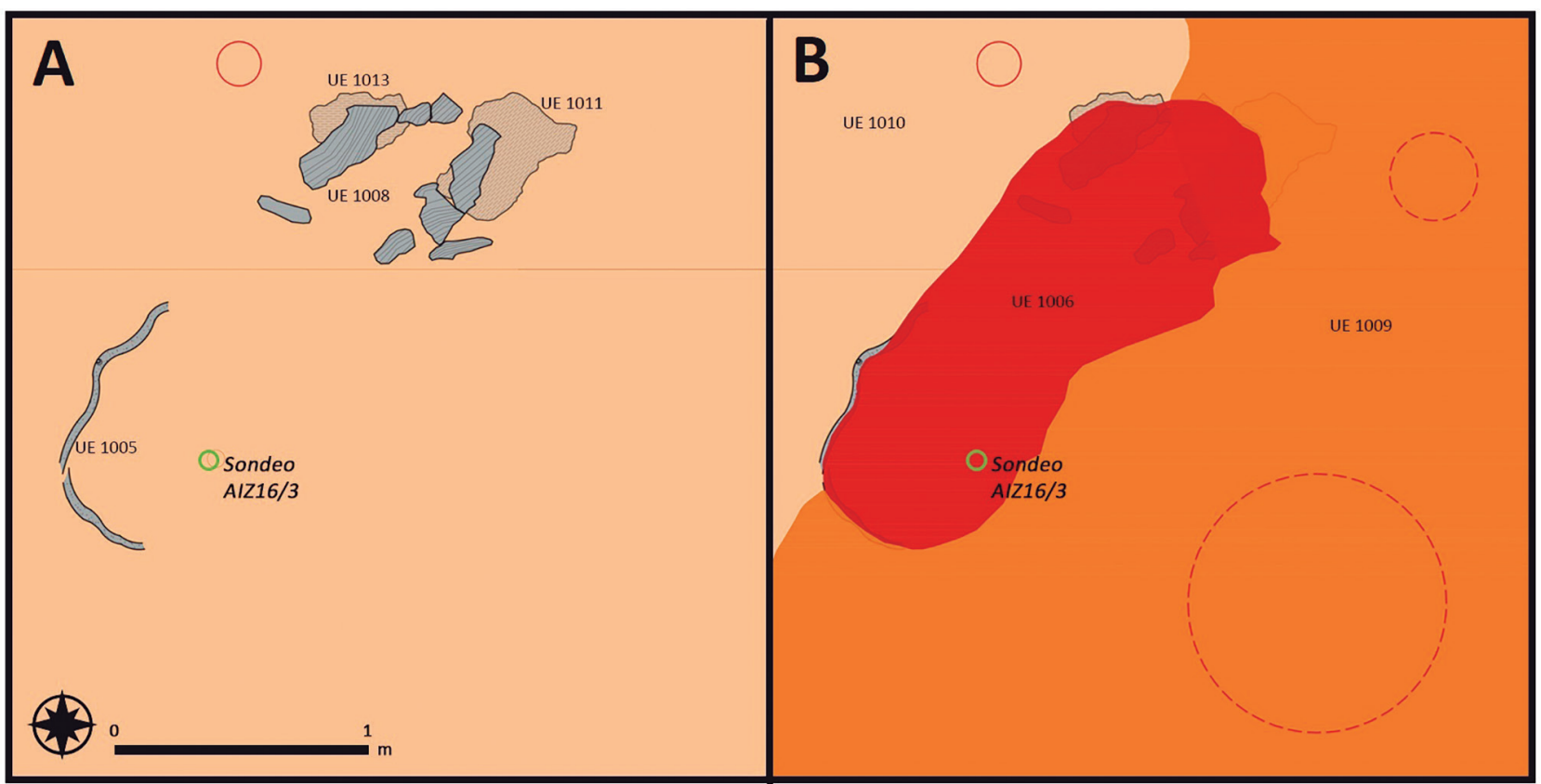

Fig. 7. A) Planos topográficos de la estructura ETK-01. Se ha excavado el sector norte, y se han documentado las UUEE 1008 , 1011 y 1013 , todas ellas compuestas por restos de madera carbonizada. B) UE 1006 cubriendo la estructura ETK-01, y estrato UE 1009, proveniente de la erosión de esta. Los círculos rojos indican los puntos de procedencia de los fragmentos de cerámica romana localizados en este nivel. Planimetría: E. Varona-Zaballa./ A) Topographic plans of the structure ETK-01. The northern sector has been excavated, allowing to document the SSUU 1008, 1011 and 1013, all of them consisting of fragments of carbonised wood. B) SU 1006 covering the structure ETK-01, and SU 1009, coming from the erosion of the former. The red circles mark the points where Roman ceramics were recovered in this level. Planimetry: E. Varona-Zaballa. 
incluye materiales cerámicos que van desde finales del siglo XVII hasta el XX. Tales materiales serían los restos de desechos domésticos que se habrían aportado como abono, tal y como está documentado etnográfica y arqueológicamente en una gran cantidad de contextos (Poirier \& Laüt 2013; Poirier 2014; 2016). En cualquier caso, este hiato que se observa entre el período tardoantiguo y el siglo XVII bien podría limitarse exclusivamente al área aquí analizada y no resultar representativa de la evolución diacrónica del asentamiento rural en su conjunto. Sería necesario ampliar las actuaciones en otros puntos de Aizarna para poder establecer conclusiones más fundamentadas sobre la secuencia de ocupación a escala local.

\section{DISCUSIÓN}

La ejecución de proyectos de investigación específicamente centrados en el estudio arqueológico de núcleos actualmente ocupados, como el que se está desarrollando en Aizarna, abren la puerta a abordar una serie de cuestiones metodológicas y conceptuales que hasta ahora han sido poco tratadas, y ofrece, por tanto, la posibilidad de proponer nuevos enfoques para el estudio de las sociedades rurales. En primer lugar, la estrategia de trabajo, basada en intervenciones puntuales poco agresivas con el entorno, pero de intensidad creciente, permite operar en el corazón mismo de unos espacios que siguen ocupados en la actualidad, ampliando posteriormente las actuaciones en los casos en los que se demuestre la existencia de registros significativos. En segundo lugar, la implementación combinada de distintas metodologías —arqueológicas, geoarqueológicas, antracológicas- posibilita realizar un análisis intensivo de tales registros, y alcanzar un alto nivel de resolución en la documentación de las secuencias de ocupación. La contrapartida a estas ventajas radica en el carácter discontinuo de las secuencias obtenidas, que se ven limitadas por la cercanía de los actuales lugares de habitación y producción. En cualquier caso, el caso de Erretorekoa evidencia el potencial del enfoque adoptado, al haber permitido establecer una secuencia estratigráfica para los últimos dos mil años.

Tanto las características de la estructura ETK-01 - probable pavimento a base de cal, alzados en madera, recubrimientos de arcilla-como los materiales recuperados — cerámicas de cocina- parecen indicar la existencia de una ocupación de carácter doméstico, que la datación radiocarbónica y la tipología de las cerámicas sitúan hacia el cambio de era, es decir, en un momento temprano del periodo altoimperial. Teniendo en cuenta su localización en el fondo de una depresión endorreica de origen kárstico y rodeada de suelos profundos con un considerable potencial agrario (Tamés Urdiain et al. 1991), resulta verosímil que esta ocupación haya podido formar parte de un hábitat estable de carácter rural, localizado en el emplazamiento del ac- tual pueblo de Aizarna. Esta hipótesis resulta coherente con otras ocupaciones conocidas en el entorno geográfico inmediato en el mismo periodo: principalmente, la cueva de Amalda, donde se recuperaron varios fragmentos de cerámica común romana y dos denarios de plata de la ceca Baskunes, estos últimos fechados en el siglo I a.C. (Armendáriz Gutiérrez 1990); pero también centros portuarios bien conectados con las redes de intercambio a escala regional, como Getaria (Alberdi Lonbide et al. 2005; Urteaga \& Arce 2011) o Zarautz (Ibáñez \& Sarasola 2009), que permiten explicar la presencia de tipologías cerámicas de gran difusión en todo el periodo antiguo, tanto en el área del Cantábrico oriental como en los vecinos valles del Adour y del Ebro (Martínez Salcedo 2004b; Esteban Delgado et al. 2012; Réchin 2013). Dicho de otra forma, todo este territorio parece intensamente habitado en época antigua por ocupaciones rurales heterogéneas y estables, que no siempre encuentran un fácil acomodo en la taxonomía arqueológica de los yacimientos rurales 'romanos' que, por otro lado, están siendo objeto de revisión y debate en la actualidad (Réchin 2011-2012; Esonde Cleary 2013; Fernández Ochoa et al. 2014; Smith et al. 2016; Allen et al. 2017)

Más allá de estas consideraciones, la ocupación de época altoimperial aparecía cubierta por un relleno fechado, al menos, entre finales del siglo III y principios del IV d.C. (UE 1004), y compuesto, entre otros, por sedimentos y diversos materiales constructivos, líticos y férreos - tanto materia prima como procesada-. Estos elementos, que fueron localizados en posición secundaria y se encontraban muy rodados, provienen probablemente del entorno circundante, aunque el mal estado de conservación de dichos materiales dificulta determinar su cronología. Es posible que se trate de elementos asociados a ocupaciones antiguas, erosionados y arrastrados en época tardoantigua, sobre los que posteriormente se fue desarrollando el actual núcleo habitado de Aizarna, reflejado en el relleno de terraza UE 1003 y en el nivel de arado, que puede datarse entre los siglos XVII y XX. Por el momento, carecemos de información suficiente para explicar el hiato que se observa entre ambos momentos, que por lo demás bien podría deberse a la parcialidad del registro aquí considerado. En cualquier caso, resulta evidente que en Aizarna se constata una clara recurrencia en la elección de los espacios de habitación, extremo que no resulta excepcional en el contexto regional ${ }^{6}$. Este hecho pone de manifiesto la relevancia de las dinámicas internas de las sociedades campesinas frente al protagonismo que históricamente se ha otorgado a factores externos como la romanización (Revilla Calvo 2004), y devuelve, por lo tanto, el interés de la investigación hacia la capacidad de adaptación y respuesta de los grupos receptores en su propio marco de relaciones sociales (González Ruibal 2006-2007).

En definitiva, cabe preguntarse hasta qué punto la aparente invisibilidad de las ocupaciones rurales de 
época antigua en el territorio guipuzcoano (Urteaga Artigas \& Arce 2011) deba explicarse desde una doble perspectiva. Por un lado, por la superposición de ocupaciones posteriores, de tal forma que muchas ocupaciones domésticas de este período podrían situarse en lugares aún hoy habitados. Por otro lado, el hallazgo de Aizarna sugiere que la entidad material de las arquitecturas de estas ocupaciones rurales puede ser tan elusiva como la de otros períodos históricos aparentemente igual de opacos — como son la Protohistoria o la Alta Edad Media-, sin que por ello debamos pensar que se trate de ocupaciones marginales o periféricas. Así lo indica, desde luego, el tipo de materiales cerámicos hallados en Aizarna, que prueban el acceso a redes de abastecimiento comunes en época romana y, por lo tanto, a la participación en sistemas económicos de escala. Por lo tanto, aunque el objetivo principal de este trabajo ha sido el de evaluar la potencialidad del estudio arqueológico de pueblos habitados, una de las principales conclusiones que pueden extraerse es la necesidad de reestudiar, desde nuevas perspectivas, la naturaleza de las ocupaciones rurales de época romana en espacios tradicionalmente considerados como escasamente ocupados.

Las intervenciones practicadas no solo han confirmado la expectativa inicial —a saber, que la investigación arqueológica de núcleos vivos puede ofrecer claves inesperadas para comprender las dinámicas sociales que imperan en el medio rural en el marco de la larga duración-, sino que abren la puerta a nuevas vías de estudio en este tipo de asentamientos. La principal aportación del enfoque experimental adoptado en Aizarna radica en el carácter progresivo de su intensidad analítica, que constituye un término medio entre la evaluación cuantitativa desarrollada por C. Lewis en los asentamientos rurales del este de Inglaterra, por un lado, y la propuesta cualitativa de excavación en extensión desarrollada en enclaves del norte peninsular, por otro. Esta estrategia transdisciplinar resulta especialmente versátil a la hora de adaptarse a las características de un entorno habitado, al permitir reforzar una de las dos vertientes del método, la cuantitativa o la cualitativa, en función de los resultados obtenidos. En un proyecto de estas características, todo ello debería traducirse en la aplicación de metodologías de intensidad creciente que nos lleven a la construcción de registros significativos en lo que se refiere a la evolución de las formas de ocupación rural en las comunidades actualmente habitadas, que nos permitan llenar los va- cíos existentes en el actual marco interpretativo y dar un sentido diacrónico a la relación que durante milenios han establecido estas comunidades con el paisaje.

\section{CONCLUSIÓN}

La experiencia del proyecto llevado a cabo en Aizarna muestra que, más allá de los problemas de legibilidad y del estado de fragmentación de los registros materiales antiguos en este tipo de contextos, la intervención arqueológica en asentamientos rurales actualmente ocupados ofrece claves interpretativas de gran interés para la comprensión de los procesos históricos que han llevado a la codificación del paisaje actual. Lejos del 'páramo' despoblado y aislado que muchas veces parecía ser el interior de la región cantábrica desde la romanización, estas investigaciones vienen a presentarnos un panorama completamente distinto, con unos grupos humanos asentados e integrados en su entorno y con una gran capacidad de adaptación a los eventos de cada momento histórico. Las sociedades campesinas aparecen, así, como sujetos activos con un rol fundamental en la construcción de los paisajes y en el establecimiento de las relaciones sociales a escala local. Asimismo, estos resultados ponen de relieve la necesidad de nuevas intervenciones en contextos rurales actualmente habitados desde una perspectiva diacrónica e integral, que permitan elaborar un marco conceptual adecuado para explicar estos procesos, extremadamente complejos, cuyos efectos a largo plazo dependen de múltiples factores endógenos y exógenos y que, todavía, no han sido suficientemente explicados. Para ello, es necesario seguir desarrollando y experimentando metodologías adecuadas a las características específicas de este tipo de contextos, que permitan tanto la elaboración de registros arqueológicos sólidos y extensivos, por un lado, como una reflexión amplia sobre las dinámicas sociales que subyacen a la codificación de los mismos, por otro.

\section{AGRADECIMIENTOS}

Este artículo se enmarca en una tesis doctoral becada con el programa PREDOC del Gobierno Vasco, así como en el proyecto de investigación "Agencia campesina y complejidad sociopolítica en el noroeste de la Península Ibérica en la Edad Media" (Ministerio de Economía, AEl/FEDER EU HUM2016-76094-C4-2-R), participado por el Grupo de Investigación en Patrimo-

\footnotetext{
${ }^{6}$ Entre otros muchos, puede citarse el caso de Momoitio; en esta localidad vizcaína, situada al pie del castro protohistórico de Tromoitio, se recuperaron varios fragmentos de cerámicas altoimperiales y tardoantiguas, ocupación que tuvo continuidad bajo la forma de una aldea altomedieval que posteriormente quedaría englobada en la actual anteiglesia de Garai, y se ha desarrollado hasta la actualidad en forma de pequeña agrupación de caseríos en torno a una ermita (García-Camino 2002). Otro ejemplo es el de Goiburu (Andoain, Gipuzkoa), donde se localizaron evidencias de ocupación de la segunda Edad del Hierro, así como de época romana, en un barrio actualmente compuesto por una ermita y varios caseríos (Pérez-Centeno 2008). También en Santa María la Real Zarautz (Gipuzkoa), cuya secuencia de ocupación arranca en la segunda Edad del Hierro y se prolonga a lo largo del periodo romano, después en forma de aldea medieval y, finalmente, como villa aforada (Ibáñez \& Sarasola 2009).
} 
nio y Paisajes Culturales (Gobierno Vasco, IT936-16) y el Grupo de Estudios Rurales (Unidad Asociada UPV/ EHU-CSIC). Los autores desean reconocer el trabajo de todas las personas que han participado en el proyecto, y en particular al equipo de excavación: Gartxot Fidalgo Urain, Francisco Gómez Díez, Aitziber González García, Aitziber Gorrotxategi Eizagirre y Asier Olazabal Uzkudun. Agradecemos su disposición y ayuda al Ayuntamiento de Zestoa y a su técnico de cultura, Fernando Arzallus Iturri; a la escuela pública de Aizarna y a su director, Aitor Zeberio; así como a todas las vecinas y vecinos de Aizarna que se interesaron y acompañaron la labor de los investigadores.

\section{REFERENCIAS}

Abel-Schaad, D., Iriarte, E., López-Sáez, J.A., Pérez-Díaz, S., Sabriego Ruiz, S., Cheddadi, R., Alba-Sánchez, F., 2018. Are Cedrus Atlantica forests in the Rif Mountains of Morocco heading towards local extinction? The Holocene, 1-15. doi: 10.1177/0959683617752842.

Abella, I., 2003. El hombre y la madera. Integrale, Barcelona.

Alberdi-Lonbide, X., 2010. Urteaga Zahar. Arkeoikuska 09, 424-425.

Alberdi-Lonbide, X., Aragón-Ruano, Á., Pérez-Centeno, J.M., 2005. Quince años de investigaciones histórico-arqueológicas en torno a Getaria. Munibe Antropologia-Arkeologia 57, 435-451.

Allen, M., Lodwick, L., Brindle, T., Fulford, M., Smith, A., 2017. The rural economy of Roman Britain: New Visions of the Countryside of Roman Britain. Society for the Promotion of Roman Studies, London.

Amondarain-Gangoiti, L., 2016. La cerámica de época romana en Oiasso-Irun. Tesis doctoral inédita. Universidad Complutense, Madrid.

Armendáriz-Gutiérrez, A., 1990. Los niveles postpaleolíticos de la cueva de Amalda. Estudio de las industrias. In: Altuna J., Baldeón A., Mariezkurrena K., La cueva de Amalda (Zestoa, País Vasco): ocupaciones paleolíticas y postpaleolíticas, 117134. Eusko Ikaskuntza, Donostia.

Aston, M., Gerrad, C., 2013. Interpreting the English Village: Landscape and community at Shapwick, Somerset. Oxbow Books, Oxford.

Ayerbe, R.M., Elorza, J., 2008. Fuentes Documentales Medievales del País Vasco, 136. Archivo Municipal de Zestoa (13381520). Eusko Ikaskuntza, Donostia.

Biester, H., Cortizas, A.M., Keppler, F., 2006. Occurrence and fate of halogens in mires. Developments in Earth Surface Processes 9, 449-464.

Cepeda-Ocampo, J.J., 2001. La romanización en los valles cantábricos alaveses. El yacimiento arqueológico de Aloria. Arabako Foru Aldundia / Diputación Foral de Álava, Vitoria-Gasteiz.

Chabal, L., 1982. Méthodes de prélèvement des bois carbonisés protohistoriques pour l'étude des relations homme-végétation. DEA, Université Montpellier II, Montpellier.

Chabal, L., 1988. Pourquoi et comment prélever les charbons de bois pour la période antique: les méthodes utilisées sur le site de Lattes (Hérault). Lattara 1, 187-222.
Chabal, L., 1994. Apports récents de l'anthracologie à la connaissance des paysages passés: performances et limites. Histoire \& Mesure 9 (3-4), 317-338.

Chabal, L., 1997. Forêts et sociétés en Languedoc (Néolithique final, Antiquité tardive): l'anthracologie, méthode et paléoécologie. Éditions de la Maisons des Sciences de l'Homme, Paris.

Chabal, L., Fabre, L., Terral, J.-F., Théry-Parisot, I., 1999. L'anthracologie. In: Ferdière, A. (ed.), La botanique, 43-104. Errance, Paris.

Chen, W., Guéguen, C., Scott-Smith, D., Galceran, J., Puy, J., Companys, E. 2018. Metal ( $\mathrm{Pb}, \mathrm{Cd}$, and $\mathrm{Zn}$ ) Binding to Diverse Organic Matter Samples and Implications for Speciation Modeling. Environmental Science \& Technology 52(7), 4163-4172.

Curtis, D.R., 2014. Coping with crisis: the resilience and vulnerability of pre-industrial settlements. Routledge, Londres / New York.

Dávila, V., 1990-1991. Zestoa. Patrimonio histórico-artístico. Informe inédito. Ayuntamiento de Zestoa.

Esmonde Cleary, S., 2013. The Roman West, AD 200-500: An Archaeological Study. Cambridge University Press, Cambridge.

Esteban-Delgado, M., Martínez-Salcedo, A., Ortega-Cuesta, L.A., Alonso, A., Izquierdo, M.T., Réchin, F., Zuluaga, M.C., 2012. La cerámica común no torneada de difusión aquitano-tarraconense (s. II a.C. - s. V d.C.): estudio arqueológico y arqueométrico. Bizkaiko Foru Aldundia / Diputación Foral de Bizkaia, Bilbao.

Etxezarraga-Ortuondo, I., 2013. San Pedro de Iromendi. Arkeoikuska 12, 270-271.

Etxezarraga-Ortuondo, I., 2014. San Pedro de Iromendi. Arkeoikuska 13, 285-289.

Etxezarraga-Ortuondo, I., 2015. San Pedro de Iromendi. Arkeoikuska 14, 311-317.

Etxezarraga-Ortuondo, I., 2016. San Pedro de Iromendi. Arkeoikuska 15, 306-311.

Faure-Boucharlat, E. (dir.), 2001. Vivre à la campagne au Moyen Âge: L'habitat rural du Ve au Xlle s. (Bresse, Lyonnais, Dauphiné) d'après les données archéologiques. ALPARA, Lyon.

Fernández-Fernández, J., 2014. Estudios multiescalares sobre la Alta Edad Media en el valle de Trubia (Asturias, España). Servicio de Publicaciones de la Universidad de Oviedo, Oviedo.

Fernández-Mier, M., Alonso-González, P., 2016. Medieval north-west Spain: What can agrarian archaeology tell us about living rural landscapes? In: Klápště, J., Agrarian technology in the medieval landscape, 291-308. Brepols, Turnhout. Ruralia X

Fernández-Mier, M., Aparicio-Martínez, P., González-Álvarez, D., Fernández-Fernández, J., Alonso-González, P., 2013. Proyecto de investigación: la formación de los paisajes agrarios del noroeste peninsular durante la Edad Media (siglos V al XII). Debates de Arqueología Medieval 3, 359-374.

Fernández-Mier, M., Fernández-Fernández, J., Alonso-González, P., López-Sáez, J.A., Pérez-Díaz, S., Hernández-Beloqui, B., 2014. The investigation of currently inhabited villages of medieval origin: Agrarian Archaeology in Asturias (Spain). Quaternary International 346, 41-55.

Fernández-Ochoa, C., Salido-Domínguez, P.J., Zarzalejos-Prieto, M., 2014. Las formas de ocupación rural en Hispa- 
nia. Entre la terminología y la praxis arqueológica. Cuadernos de Prehistoria y Arqueología de la Universidad Autónoma de Madrid 40, 111-136.

Figueiral, I., Mosbrugger, V., 2000. A review of charcoal analysis as a tool for assessing Quaternary and Tertiary environments: achievements and limits. Palaeogeography, Palaeoclimatology \& Palaeoecology 164, 397-407.

Francovich, R., Hodges, R., 2003. Villa to Village. The Transformation of the Roman Countryside in Italy, C. 400-1000. Bloomsbury Academic, Londres.

García-Camino, I., 2002. Arqueología y poblamiento en Bizkaia, siglos VI-XII. La configuración de la sociedad feudal. Bizkaiko Foru Aldundia / Diputación Foral de Bizkaia, Bilbao.

Gentili, F., Lefèvre, A. (eds.), 2009. L'habitat rural du haut Moyen Âge en Île-de- France. Guiry-en-Vexin: 2ème supplément au Bulletin archéologique du Vexin français et du Val-d'Oise.

González-Ruibal, A., 2006-2007. Galaicos: poder y comunidad en el Noroeste de la Península Ibérica (1200 a.C. - 50 d.C.). Brigantium 18, 11-272.

Greguss, P., 1955. Identification of Living Gymnosperms on the Basis of Xylotomy. Akadémiai Kiadó, Budapest.

Hamerow, H., 2002. Early Medieval Settlements. The Archaeology of Rural Communities in North-West Europe 400-900. Oxford University Press, Oxford.

Hamerow, H., 2012. Rural Settlement and Society in Anglo-Saxon England. Oxford University Press, Oxford.

Hidalgo, J., 2014. Elexazar. Arkeoikuska 13, 45-49.

Hotelling, H., 1933. Analysis of a Complex of Statistical Variables with Principal Components. Journal of Educational Psychology 24(7), 498-520

Ibáñez-Etxeberria, Á., Sarasola-Etxegoien, N., 2009. El yacimiento arqueológico de Santa María la Real de Zarautz (País Vasco). In: Ibáñez-Etxeberria, Á. (ed), Santa María la Real de Zarautz. Continuidad y discontinuidad en la ocupación de la costa vasca entre los siglos V a.C. y XIV d.C. Sociedad de Ciencias Aranzadi Zientzia Elkartea, Donostia. Munibe. Suplemento, 27.

International Colloquium: Archaeology of Medieval Villages currently inhabited in Europe, Oxford, 7 mayo 2016. Available from: https://archaeologymedievalvillages.wordpress.com/ [consultado: 11-06-2018].

Johnson, M., 2006. Ideas of landscape. Wiley, Londres.

Kirchner, H., 2010. Por una arqueología agraria. Perspectivas de investigación en las sociedades medievales hispánicas. Archaeopress, Oxford.

Kluiving, S.J., Guttmann-Bond, E., 2012. Landscape Archaeology between Art and Science: from a multi- to an interdisciplinary approach. Amsterdam University Press, Amsterdam.

Krosshavn, M., Steinnes, E., Varskog, P., 1993. Binding of Cd, $\mathrm{Cu}, \mathrm{Pb}$ and $\mathrm{Zn}$ in soil organic matter with different vegetational background. Water Air Soil Pollut. 71, 185-193.

Leri, A.C., Myneni, S.C.B., 2012. Natural organobromine in terrestrial systems. Geochimica et Cosmochimica Acta 77, 1-10.

Lewis, C., 2007. New Avenues for the Investigation of Currently Occupied Medieval Rural Settlement: Preliminary Observations from the Higher Education Field Academy. Medieval Archaeology 51, 133-163

Lewis, C., 2010. Exploring Black Holes: Recent Investigations in Currently Occupied Rural Settlements in Eastern England.
In: Higham, N., Ryan, M. (eds.), The Landscape Archaeology of Anglo-Saxon England, 83-106. Boydell and Brewer, Suffolk.

Lewis, C., 2014. The power of pits: archaeology, outreach and research in living landscapes. In: Boyle, K., Rabett, R.J., Hunt, C.O. (eds.), Living in the landscape. Essays in honour of Graeme Barker, 321-338. McDonald Institute for Archaeological Research, Cambridge.

Lewis, C., 2017. Test pit excavation within currently occupied rural settlements: results of the English CORS project in 2016. Medieval Settlement Research 32, 70-78.

López-González, G., 1982. La guía de INCAFO de los árboles y arbustos de la Península Ibérica. Incafo, Madrid.

Marguerie, D., Hunot, J.-Y., 2007. Charcoal analysis and dendrology: data from archaeological sites in north-western France. Journal of Archaeological Science 34, 1417-1433.

Martínez-Salcedo, A., 2004a. Arqueología e historia del periodo romano en Bizkaia (1972-2002). Kobie. Anejos 6(1), 353-370.

Martínez-Salcedo, A., 2004b. Cerámica común de época romana en el País Vasco = Erromatarren garaiko zeramika arrunta Euskal Herrian. Eusko Jaurlaritza / Gobierno Vasco, Bilbao.

Moshenska, G., 2017. Key concepts in public archaeology. UCL Press, Londres.

Orejas-Saco del Valle, A., 2006. Arqueología espacial: espacios agrarios. Seminario de Arqueología y Etnología turolense, Teruel.

Pérez-Centeno, J.M., 2008. San Esteban de Goiburu. Primer yacimiento localizado en el valle del Oria con niveles de la Edad del Hierro y época romana. Leyçaur 10, 17-62.

Peytremann, E., 2003. Archéologie de l'habitat rural dans le nord de la France du IVe au XIle siècle. Association Française d'Archéologie Mérovingienne, Saint-Germain-en-Laye.

Poirier, N., 2016. Archaeological evidence for agrarian manuring: Studying the time-space dynamics of agricultural areas with surface-collected off-site material. In: Klápště, J., Agrarian technology in the medieval landscape, 279-290. Brepols, Turnhout.

Poirier, N., 2014. Indices archéologiques d'intensification agraire et dynamiques spatiales des terroirs. In: Viader, R., Rendu, C. (eds.), Cultures temporaires et féodalité. Les rotations culturales et l'appropriation du sol dans l'Europe médiévale et moderne, 117-132. Presses Universitaires du Mirail, Flaran.

Poirier, N., Laüt, L., 2013. Approches comparées du mobilier hors-site: Peut-on cerner l'espace agraire antique? In: Gandini, C., Laüt, L. (eds.), Regards croisés sur le Berry ancien: sites, réseaux et territoires. 45e supplément à la Revue Archéologique du Centre de la France, 113-133. ARCHEA-FERAFC, Tours.

Ruiz del Árbol-Moro, M., 2006. La arqueología de los espacios cultivados. Terrazas y su explotación agraria romana en un área de montaña: la Sierra de Francia (Salamanca). CSIC - Instituto de Historia, Madrid.

Quirós-Castillo, J.A., 2006. La génesis del paisaje medieval en Álava: la formación de la red aldeana. Arqueología y Territorio Medieval 13(1), 49-94.

Quirós-Castillo, J.A., 2011. Despoblados medievales alaveses. Arkeoikuska 11, 23-32. 
Quirós-Castillo, J.A. (dir.), 2012. Arqueología del campesinado medieval: la aldea de Zaballa. Documentos de Arqueología Medieval 3. Euskal Herriko Unibertsitatea / Universidad del País Vasco, Bilbao.

Quirós-Castillo, J.A., 2014. Oltre la frammentazione postprocessualista: archeologia agraria nel nordovest della Spagna. Archeologia Medievale 41, 23-38.

Quirós-Castillo, J.A. (dir.), 2018. Arqueología de una comunidad campesina medieval: Zornoztegi (Álava). Documentos de Arqueología Medieval 13. Euskal Herriko Unibertsitatea / Universidad del País Vasco, Bilbao.

Réchin, F., 2011-2012. Pour une approche positive des espaces périphériques de l'empire romain. L'Aquitaine méridionale à la fin de l'âge du Fer et à l'époque romaine. Caesarodunum 45-46, 357-391.

Réchin, F., 2013. Transferts de technologie en Aquitaine méridionale à la fin du second Âge du Fer et au début de l'époque romaine. L'exemple des céramiques communes. Mélanges de la Casa de Velázquez 43-1, 141-172.

Revilla-Calvo, V., 2004. El poblamiento rural en el noreste de Hispania entre los siglos II a.C. y I d.C.: Organización y dinámicas culturales y socioeconómicas. In: Moret, P., Chapa, M.T., Torres, atalayas y casas fortificadas: explotación y control del territorio en Hispania (s. III a. de C.- s. I d. de C.), 175-202. Universidad de Jaén, Jaén.

Rippon, S., 2009. Understanding the Medieval Landscape. In: Gilchrist, R.R., Reynolds, A. (eds.), 50 years of medieval archaeology in Britain and beyond 1957-2007, 227-254. Routledge, Londres.

Rippon, S., 2014. Beyond the Medieval Village. Oxford University Press, Oxford.

Salsamendi-Serrano, I., 2007. Estudio del material cerámico postmedieval recuperado en contextos de arqueología urbana de la Comunidad Autónoma Vasca. Inédito.

Schofield, J., 1991. The Construction of Medieval and Tudor Houses in London. Construction History 7, 3-28.

Schweingruber, F.H., 1990. Anatomy of European Woods. Paul Haupt, Berna.

Smith, A., Allen, M., Brindle, T., Fulford, M., 2016. The rural settlement of Roman Britain. Society for the Promotion of Roman Studies, London.

Tamés-Urdiain, P., Mendiola-Gómez, I., Pérez-Olozaga, C. (eds.), 1991. Geomorfología y edafología de Gipuzkoa. Gipuzkoako Foru Aldundia / Diputación Foral de Gipuzkoa, Donostia

Ugalde, T., 1984. Estudio de las cuencas hidrogeológicas de Akua y Aizarna (Zestoa). Munibe Ciencias Naturales 36, 23-64.

Urteaga-Artigas, M.M., Arce, J., 2011. Arqueología Romana en Gipuzkoa $=$ Erromatar Arkeologia Gipuzkoan. Gipuzkoako Foru Aldundia / Diputación Foral de Gipuzkoa, Donostia.

Valais, A. (ed.), 2012. L'habitat rural au Moyen Âge dans le Nord-Ouest de la France. Presses Universitaires de Rennes, Rennes.

Valenti, M., 2004. Insediamento altomedievale nelle campagne toscane. Paesaggi, popolamento e villaggi tra VI e X secolo. All'insegna del Giglio, Florencia.

Van Pée, K.H., Unversuch, S., 2003. Biological dehalogenation and halogenation reactions. Chemosphere 52, 299-312.
Vernet, J.-L., Ogereau, P., Figueiral, I., Machado-Yanes, C., Uzquiano, P., 2001. Guide d'identification des charbons de bois préhistoriques du sud-ouest de l'Europe. CNRS Éditions, Paris.

Vignote-Peña, S., Picos-Martín, J., Zamora-Paniagua, R., 2000. Características de las principales maderas utilizadas en Bizkaia: Tecnología y aplicaciones. Bizkaiko Foru Aldundia / Diputación Foral de Bizkaia, Bilbao. 